\title{
Article \\ Multitemporal Change Detection Analysis in an Urbanized Environment Based upon Sentinel-1 Data
}

\author{
Lars Gruenhagen (D) and Carsten Juergens * (D)
}

Citation: Gruenhagen, L.; Juergens, C. Multitemporal Change Detection Analysis in an Urbanized Environment Based upon Sentinel-1 Data. Remote Sens. 2022, 14, 1043. https://doi.org/10.3390/rs14041043

Academic Editors:

Constantinos Cartalis and Fulong Chen

Received: 15 December 2021 Accepted: 18 February 2022 Published: 21 February 2022

Publisher's Note: MDPI stays neutral with regard to jurisdictional claims in published maps and institutional affiliations.

Copyright: (C) 2022 by the authors. Licensee MDPI, Basel, Switzerland. This article is an open access article distributed under the terms and conditions of the Creative Commons Attribution (CC BY) license (https:// creativecommons.org/licenses/by/ $4.0 /$ )
Institute of Geography, Faculty of Geosciences, Ruhr-University Bochum, D-44870 Bochum, Germany; lars.gruenhagen@rub.de

* Correspondence: carsten.juergens@rub.de

\begin{abstract}
The German Ruhr area is a highly condensed urban area that experienced a tremendous structural change over recent decades with the replacement of the coal and steel industries by other sectors. Consequently, a lot of major land cover changes happened. To retrospectively quantify such land cover changes, this study analysed synthetic aperture radar images of the Sentinel-1 satellites by applying the Google Earth Engine. Three satellite images are analysed by the multitemporal difference-adjusted dispersion threshold approach to capture land cover changes such as demolished buildings and new buildings by applying a threshold. This approach uses synthetic aperture radar data that are rarely considered in previously existing land cover change services. Urbanization or urban sprawl leads to changes in the urban form globally. These can be caused, for example, by migration or regionally by structural change, etc., such as in the study area presented here. The results are validated with reference data sets, which are publicly available nationally (e.g., house contour lines, normalized digital terrain model, digital orthophotos) or which are publicly available globally like the Global Urban Footprint and the World Settlement Footprint. Based on this, land cover changes could be identified for 21 locations within the study area of the city of Bochum.
\end{abstract}

Keywords: multitemporal assessment; SAR; Sentinel-1; LULCC; Ruhr area; Bochum; Google Earth Engine

\section{Introduction}

The German Ruhr area is characterized as a highly condensed urban area. During recent decades, this region has experienced a tremendous structural change with the replacement of the coal and steel industries by service-oriented sectors. This conversion induced a lot of major land cover changes that accordingly caused changes to the urban form.

On the one hand, urban form is defined by its spatial location [1-4], and on the other hand, it is defined by its characteristics and functions. For example, an urban settlement could be a city with market rights, suburbs or a central business district [5]. These different functions determine the daily life-satisfaction of the needs of the local residents, like mobility [6], health promotion [7] as well as interaction and communication [8,9].

To be able to spatio-temporally analyse urban form comparably on a global scale, Wentz et al., 2018 developed a concept based on three main categories/components (materials, configuration and time/dynamics) and six secondary aspects (Figure 1). The main component materials consider the aspects of human constructions, soil-plant continuum and surface water. The second main component, configuration, considers the aspects of dimensionality and spatial pattern. The third main component, time/dynamics, considers only one associated aspect called "time" [10].

In this article, the urban form is analysed especially under four selected aspects (Figure 1). From the materials category, human constructs are analysed, especially building demolitions and new buildings. Under the category of configuration, urban form is described in two dimensions and the spatial pattern in terms of the spatial extent of buildings. In the category time/dynamics, these previously described aspects are investigated multitemporaly between three points in time. For this purpose, Earth observation data are used. 


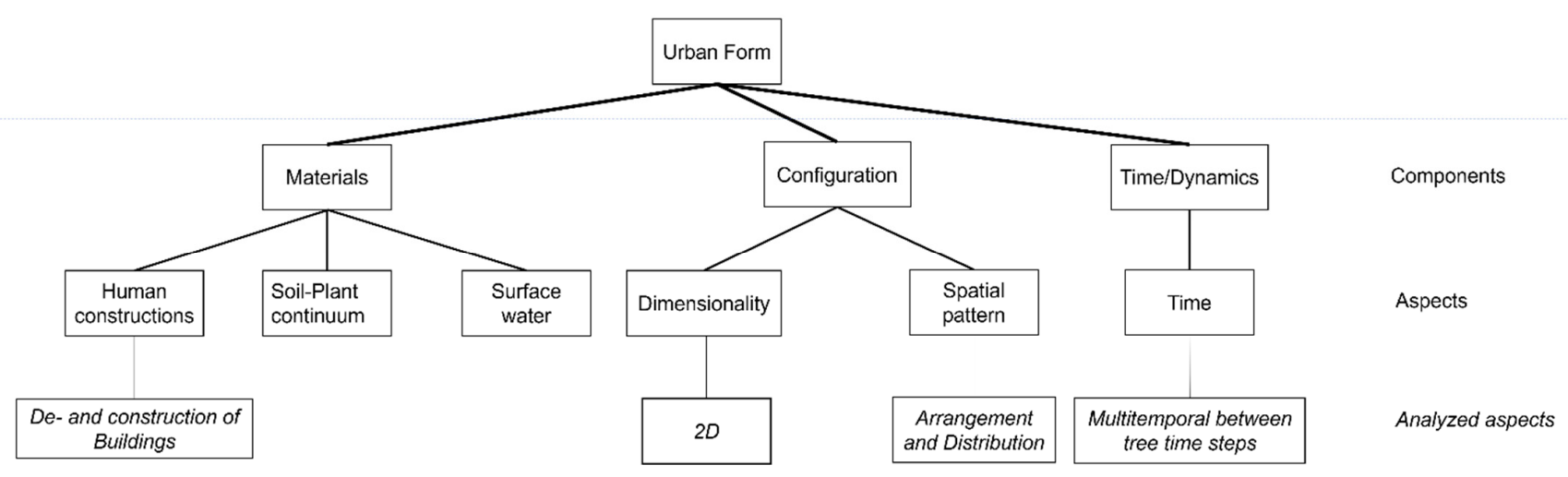

Figure 1. Fundamental components and aspects of urban form. (Figure adapted from [10]).

Due to the small heterogeneous structure but also due to the fast processes like urban sprawl in urban areas, Earth observation data are especially suitable as the data basis [11]. However, they also have some advantages and disadvantages due to their respective resolution and characteristics. A bridge to the analysis of urban areas with earth observation data is built by Netzband \& Jürgens 2010 [12]. Land cover change analysis can be done with optical data, e.g., in Jürgens 2000 [13], but also as in this study with active synthetic aperture radar (SAR) data.

To detect land cover changes from multitemporal SAR data, various mathematical, statistical, and rule-based classification methods exist. These can be based on pixels, objects or features [14].

A simple mathematical approach is to determine the log ratio between two records of the respective backscatter. Above a certain threshold, a land cover change is then detected [15]. It assumes that if the land cover remains constant, the backscatter does not change over time. Land cover changes alter the backscatter so that a change can be determined $[16,17]$. Also, multitemporal SAR data can be supplemented with multispectral data e.g., from Sentinel-2, QuickBird, Worldview, etc. Thus, land cover changes can be detected by indices or calculations [18-20], this also represents a first pixel-based data fusion of active and passive data on sensor data [21].

Several approaches are based on the respective statistical distributions of backscatter, which use different statistical parameters to determine thresholds for when a backscatter represents a land cover change and when it does not. This can be done by determining the ratio or difference, etc., from multiple images [22]. In addition, multidimensional probability distributions such as by the Kullback-Leibler divergence can capture land cover changes $[23,24]$.

It is also possible to determine automatically generated threshold values via the multivariate distribution between two quadratic and geometric mean values. This reduces the false alarm rate and simplifies the decision whether a change is really present [25].

Furthermore, a variety of likelihood ratio tests can also be used. These tests then decide whether there is a change between the recording times. This method has been used previously for different sensors using a polarimetric Wishart distribution [17,26-29]. Bayesian networks are also used. These create directed acyclic graphs to capture land cover changes that represent random variables and dependencies based on probabilities $[17,24,30-32]$.

Increasingly, methodological approaches from image classification are used. First, object-based approaches for geometric feature detection and semantic cluster detection with segmentation $[33,34]$. Often, AI networks are used for feature-based approaches using statistical methods such as fuzzy logic. Less commonly, decision rule-based approaches are used. These represent a complete data fusion by producing coherent data sets. Here, optical data, e.g., from Landsat and SAR data, e.g., from ALOS PALSAR, are processed completely independently [24,34-38]. 
In this study, the multitemporal difference-adjusted dispersion threshold (MDADT) method is used. It is similar to the Rapid and Easy Change detection on Time series using the coefficient of Variation (REACTIV) approach of Koeniguer \& Nicolas 2020 [17]. Land cover changes are represented in the hue saturation value (HSV) colour space. In this colour space, the respective brightness and chromaticity are considered. This colour space is determined by the Hue colour value colour angles in the colour wheel (from purple-blue-green yellow, red). In this way, the respective intensity of the colour can be represented [39]. Land cover changes are determined using the theoretical mean value of the Rayleigh Nakagam distribution. This approach is suitable for representing land cover changes [17]. Small-scale changes (approximately $<1500 \mathrm{~m}^{2}$ ) are not captured by the REACTIV method [40].

Similar to the REACTIV method described above, this article uses land cover change thresholds by the difference between the images via multiplying the standard deviation by a factor of 1.5 and adding the mean. This MDADT method allows for a straightforward and simple robust detection of land cover change-outliers in the distribution to be identified. This approach also allows changes to be represented using additive colour mixing in the red green blue (RGB) colour space. Here, the colours red, green and blue are additively combined in the colour space. [39]. In the case of a land cover change, this is then represented in the respective assigned colour of the time of the change. If there is no land cover change, it is displayed in white or grey shades.

In Earth observation analyses, this method has been used for a wide range of applications [41-43].

Small-scale changes are underrepresented in the REACTIV method. Therefore, it is necessary to investigate whether it is possible, by means of a weighted threshold, to capture multitemporal changes in urban form using further high-resolution public, partly freely available vector and raster geospatial data. For this purpose, logarithmically scaled Sentinel-1 data are processed and analysed in Google Earth Engine [44,45].

To validate this analysis, an area is selected that is well documented by third-party geospatial data and known to have had land cover changes.

The goal of the study is to use the MDADT method to record land cover changes in the form of building demolitions and new construction. These changes will be validated with third party geospatial data. Another goal is to be able to transfer this methodology to less well-documented areas.

\section{Materials and Methods}

\subsection{Study Area}

The selected study area (4312.67 ha) is located in eastern Bochum, North RhineWestphalia, Germany (Figure 2). Thus, it is centrally located in the Ruhr area, one of the largest agglomerations in Europe with more than 5 million inhabitants.

The Ruhr region is a highly dense urban area. It has experienced significant structural change in recent decades, with heavy industry (coal \& steel) increasingly being replaced by other industries. As a result, there have been serious changes in land cover.

The study area in the east of Bochum is representative for the Ruhr area. It contains urban areas of varying density, as well as agricultural, forested and water areas. Furthermore, it is characterized by significant land cover changes in recent years [46]. It has been strongly influenced by the economic globalization-based plant closure of the Opel factory (General Motors). With the guiding principle of a knowledge-based economy, the focus is now much more on a more diversified industry structure. Particular focus is placed on the service sector, e.g., logistics, and on research and development by numerous universities [47]. 


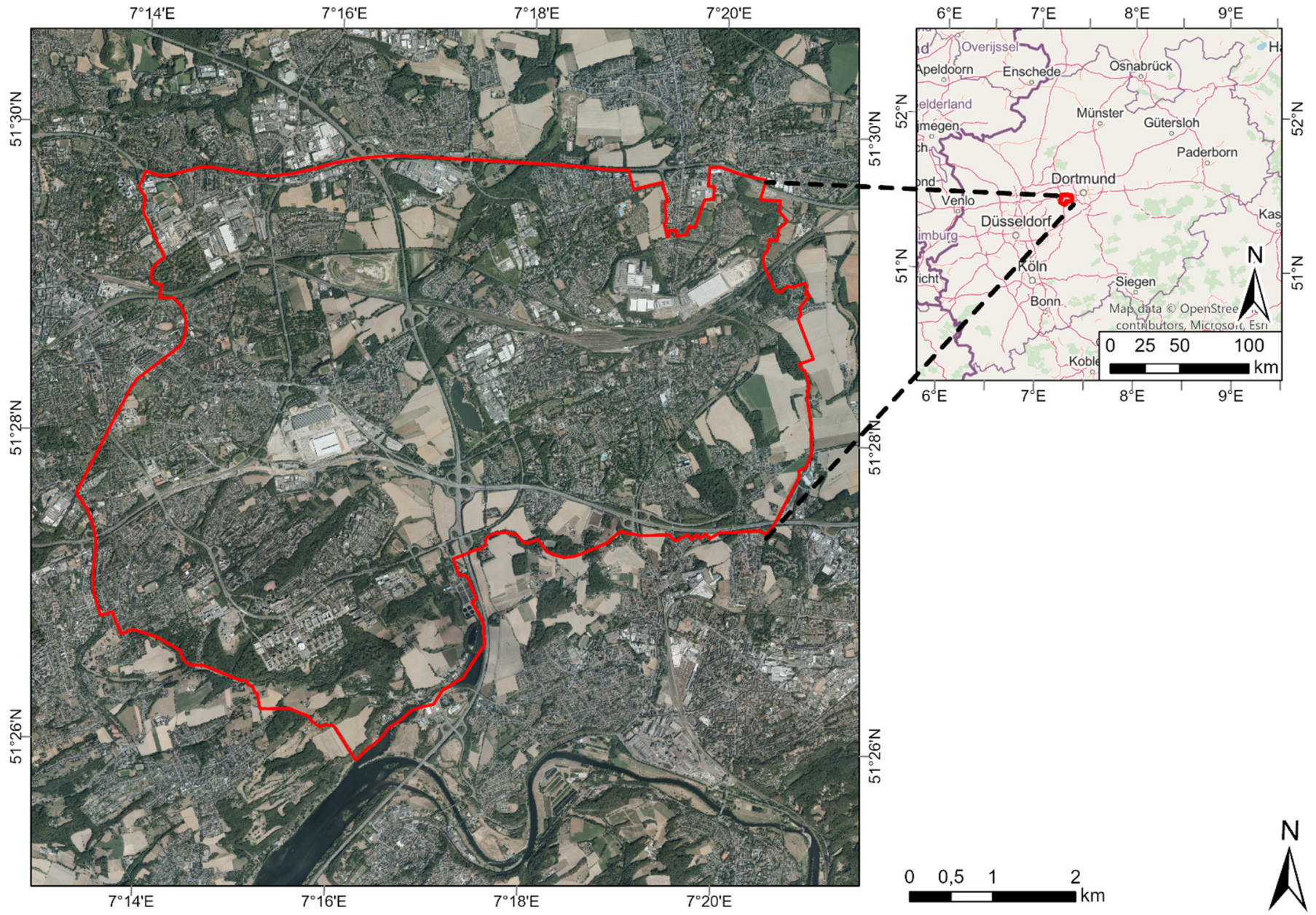

Figure 2. Right: overview map with indicated study area in Bochum, North Rhine-Westphalia, Germany [48]. Left: study area in the eastern part of Bochum [49].

\subsection{Spatial Data}

Open-source Sentinel-1 data were available for the study (Table 1).

Table 1. Characteristics of the Sentinel-1 Data [50-52].

\begin{tabular}{cc}
\hline Specifications & Sentinel-1 \\
\hline Dates and time & A 7 January 2015, 4:41:45 a.m. \\
(YYYY-MM-DD) & B 7 January 2017, 4:49:26 a.m. \\
Ground Resolution in $\mathrm{m}$ & 10 \\
Azimuth Resolution in $\mathrm{m}$ & 20 \\
moderate geometric resolution & $5 \mathrm{~m}$ by $20 \mathrm{~m}$ \\
Polarization & Dual $(\mathrm{VV}-\mathrm{VH})$ \\
Frequency & C-Band \\
Sensor mode & IW \\
Mode & Interferometric wide (SLC) \\
Incidence Angle & $18.3^{\circ}-46.8^{\circ}$ \\
Coverage in km & $>250$ km $\times 100 \mathrm{~km}$ \\
Processing level: & thermal noise corrected, Radiometric calibration, Terrain correction \\
Orbit direction & (SRTM) and converted to decibels via log scaling $(10 * \log 10(\mathrm{x}))$. \\
\hline
\end{tabular}

The three datasets from 1 July 2015, 1 July 2017, and 1 May 2020 are from the first days of January and were used to exclude land cover changes that occured due to changing 
agricultural land use. These could occur in recordings from the summer months, as land cover changes occur in arable crop production due to crop-specific planting and harvest dates.

Precipitation values from the nearby Ludger Mintrop weather station indicate that no significant rainfall events greater than $10 \mathrm{~mm}$ occurred prior to the image acquisition, and thus the capture of changes in urban form is not affected by surface water.

The following third party geospatial data are used to validate the recorded land cover changes (Table 2). On the one hand, house perimeters; they are a follow-up product of the ALKIS (Authoritative Real Estate Cadastre Information System) data [53]. On the other hand, the normalized NDSM, which is the product of the orthogeometry of the aerial photographs and the DTM from the LiDAR survey [54].

As a further data set, the Global Urban Footprint (GUF) was used, which is based on radar images from TerraSAR-X/TanDEM-X. DLR globally provides data on sealing in about $5 \times 10 \mathrm{~m}$ resolution upon request [55-58].

In addition, the World Settlement Footprint (WSF) dataset was used to represent more recent land cover changes. It is based on different datasets [57,59].

In addition, the German base map 1:5000 from 2016 was used, as it shows the entire Opel plant I including house perimeters [60].

\subsection{Methodology}

In the following, the methodology of the MDADT method is described in detail, it extracts land cover changes from multitemporal Sentinel- 1 images. These represent building demolitions and new construction. Then, the changes are validated with thirdparty geospatial data to verify the captured changes.

Figure 3 shows the individual intermediate steps of the MDADT method described below. In Google Earth Engine, the selected Sentinel-1 (Table 1) were used with the mode IW from the descending path in ten meters resolution and in VV, VH polarization. Then the images were filtered with the speckle filter focal mean in a $50 \mathrm{~m}$ radius (Figure 3, data input).

For the multitemporal visualisation, the individual VH images were chronologically assigned to the three primary colours red, green and blue in one image using additive colour mixing (Figure 3, processing).

Objects that are detected only at one point in time in the radar image are displayed in the primary colour assigned to that image. If land cover changes occur between the three points in time, they are displayed in the respective mixed colour of the primary colours involved.

In yellow land cover changes between the first (2015) and second (2017) image are shown, in cyan blue land cover changes between the second (2017) and third (2020) and in magenta land cover changes between the first (2015) and third (2020) image are shown.

If buildings are constructed or demolished, these land cover changes are shown in the respective colour of the time period, allowing a very accurate record of the respective time of land cover change. Areas where no land cover changes occur are shown in white or grey tones.

Land cover changes can also be temporary, such as parked vehicles or containers in a parking/storage area. Land cover changes also occur periodically, such as vegetation, but this is nearly ruled out by the January imagery. Furthermore, chaotic backscatter can occur due to meteorological effects or metallic objects in radar images.

In order to determine differences between the three images, the respective difference between the acquisition times of the VH polarizations was calculated in Google Earth Engine. From this difference, land cover changes can be extracted by threshholding. For this purpose, the threshold value was statistically determined by multiplying the standard deviation of the difference of the images by a factor of 1.5 and adding the mean value of the difference of the images (Figure 3, processing).

For further quantification, the respective grid cells greater than or equal to 10 for buildings were extracted from the differences between the three images. Thus, land cover changes in the form of new building construction can be identified (Figure 3, processing). 
Table 2. Characteristics of third party geospatial data sets (Source authors).

\begin{tabular}{|c|c|c|c|c|c|}
\hline Specifications $\backslash$ Data & $\begin{array}{l}\text { Building } \\
\text { Footprints } \\
\text { (BF) }\end{array}$ & $\begin{array}{l}\text { Normalized Digital Surface } \\
\text { Model (nDSM) }\end{array}$ & Digital Orthophotos (DOP) & $\begin{array}{l}\text { Global } \\
\text { Urban } \\
\text { Footprint } \\
\text { (GUF) }\end{array}$ & $\begin{array}{l}\text { World Settlement Footprint } \\
\text { (WSF) }\end{array}$ \\
\hline Coverage & NRW & NRW & NRW & $\begin{array}{c}\text { Global } \\
\left(60-75^{\circ} \mathrm{N}\right)\end{array}$ & $\begin{array}{c}\text { Global } \\
\left(74^{\circ} \mathrm{N}-56^{\circ} \mathrm{S}\right)\end{array}$ \\
\hline Spatial resolution & $1: 1$ & $50 \mathrm{~cm}$ & $10 \mathrm{~cm}$ & $12 \mathrm{~m}\left(0.4^{\prime \prime}\right)$ & $10 \mathrm{~m}$ \\
\hline Temporal reference & 2020 & 2018-2019 & 2018 & 2011-2012 & 2015-2019 \\
\hline Output data & ALKIS-objects & $\begin{array}{c}\text { Dense-Image-Matching based on } \\
\text { digital aerial photos and lidar } \\
\text { data }\end{array}$ & $\begin{array}{l}\text { Orthorectified digital aerial } \\
\text { photos }\end{array}$ & $\begin{array}{l}\text { 180,000 intensity images } 3 \mathrm{~m} \\
\text { ground resolution (spotlight } \\
\text { mode) from TerraSAR-X SAR } \\
\text { 2018: Sentinel-1 \& -2 }\end{array}$ & $\begin{array}{l}\text { 217,000 Landsat-8 and 107,000 } \\
\text { Sentinel-1 images, High } \\
\text { Resolution Settlement Layer } \\
\text { (HRSL) Digital Globe VHR } \\
\text { satellite imagery and publicly } \\
\text { released at } 30 \mathrm{~m}, 2019 \text { Sentinel-1 } \\
\text { 1,2 Mio. and Sentinel-2 1,8 Mio. }\end{array}$ \\
\hline $\begin{array}{c}\text { Position projection-Reference } \\
\text { System } \\
\text { EPSG }\end{array}$ & 4647 & 25,832 & 25,832 & 4326 & 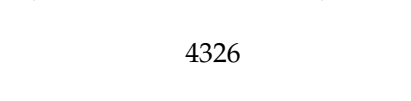 \\
\hline $\begin{array}{c}\text { Height projection- } \\
\text { Reference System } \\
\text { EPSG }\end{array}$ & / & 7837 & 7837 & / & / \\
\hline Data format & SHP & TIF & TIF & TIF & TIF \\
\hline Version & / & / & / & 2 & 2 \\
\hline $\begin{array}{l}\text { Geometric resolution } \\
\text { Scale }\end{array}$ & / & $\pm 5 \mathrm{dm}$ in position and height & $\pm 2-3 \mathrm{dm}$ & / & / \\
\hline $\begin{array}{l}\text { Thematic accuracy } \\
\text { Production time }\end{array}$ & $\begin{array}{c}/ \\
2020\end{array}$ & $\begin{array}{c}/ \\
2018\end{array}$ & $\begin{array}{c}\prime \\
2018\end{array}$ & $\begin{array}{c}85 \% \\
2016-2018\end{array}$ & $\begin{array}{c}100-75 \% \\
2015 / 2019\end{array}$ \\
\hline Accessibility & Open data & Open data & Open data & $\begin{array}{l}\text { Free Request for non-commercial } \\
\text { used }\end{array}$ & $\begin{array}{l}\text { Free Request for non-commercial } \\
\text { used }\end{array}$ \\
\hline License & $\begin{array}{c}\text { Datenlizenz } \\
\text { Deutschland-Zero-Version } 2.0\end{array}$ & $\begin{array}{c}\text { Datenlizenz } \\
\text { Deutschland-Zero-Version } 2.0\end{array}$ & $\begin{array}{c}\text { Datenlizenz } \\
\text { Deutschland-Zero-Version } 2.0\end{array}$ & Research: free of charge & Research: free of charge \\
\hline $\begin{array}{c}\text { Source-Responsible organisation } \\
\text { Reference }\end{array}$ & $\begin{array}{c}\text { GEOBASIS NRW } \\
\text { [53] }\end{array}$ & $\begin{array}{c}\text { GEOBASIS NRW } \\
{[54]}\end{array}$ & $\begin{array}{c}\text { GEOBASIS NRW } \\
{[49]}\end{array}$ & $\begin{array}{l}\text { DLR } \\
{[61]}\end{array}$ & $\begin{array}{c}\text { DLR } \\
{[57,59]}\end{array}$ \\
\hline
\end{tabular}




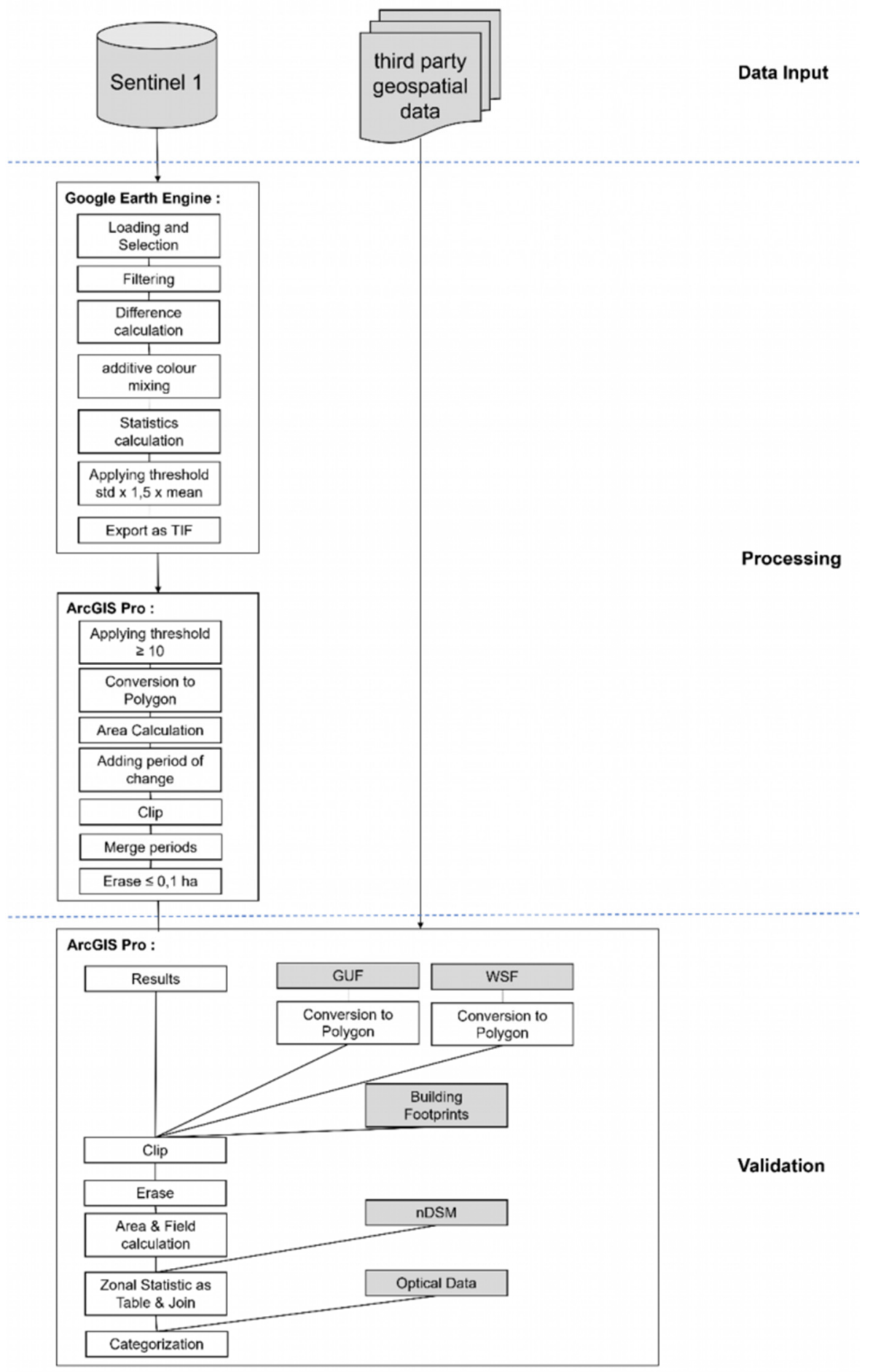

Figure 3. Described workflow in a flow chart.

This threshold was determined empirically in the individual images. After extracting the building pixels, the raster dataset is converted to a polygon dataset, as this simplifies validation with third party geospatial data and provides a better representation of results (Figure 3, processing).

Subsequently, the area of land cover changes was calculated and the respective time period (2015-2017, 2017-2020, and 2015-2020) between which the land cover changes that occurred were inserted into the attribute table (Figure 3, processing). 
To identify the actual land cover changes that occurred due to buildings, a clip was made between the land cover changes and the extracted buildings for the respective time periods. The results were merged with attributes of the respective time period to uniquely identify these areas with land cover changes (Figure 3, processing).

Subsequently, these results were validated with third party geospatial data (Figure 3, validation). Land cover changes of less than 0.1 ha were not considered-they were found to be erroneously recorded land cover changes. First, the results were blended with the house perimeters and afterwards, residual areas were calculated to identify areas that could not be explained by the house perimeters (Figure 3, validation).

From these ratios between the remaining area and the initial area, areas can be identified where the ratio is not equal to one. From these remaining areas, the average height of the polygons was determined, whereby only building heights higher than five meters were examined. The connecting polygons were validated via digital orthophotos or with images from Planet Earth Explorer and Google Earth in this period (Figure 3, validation).

The results of the validation were then categorized in terms of their way of changing the urban form in the attribute table. In the investigated category materials, a distinction is made between the type of change of human constructs: building demolitions and new buildings. The land cover changes recorded above were manually classified into the following categories:

- $\quad$ New buildings (constructed), e.g., university buildings or dormitories;

- $\quad$ Building demolition (deconstructed), e.g., former Opel factory buildings;

- Building demolition and subsequent new construction on the same area (deconstructedconstructed), e.g., on the southern area of Opel plant I by DHL distribution centre;

- $\quad$ SAR interaction with metallic objects on the ground surface (metal), e.g., different number and location of containers.

In relation to spatial patterns of urban form, the spatial extension-size of buildings is divided. They are divided into three groups according to their size:

- $\quad$ large areas (large) (>1 ha),

- medium-sized areas (middle) (0.1-1 ha),

- $\quad$ small areas (small) $(<0.1 \mathrm{ha})$.

These two divisions by type of change and size were evaluated for the type of urban form. In addition, the final results converted to polygons from Google Earth Engine were saved as polygons using the globally available GUF and WSF data from DLR. These data larger than 0.1 ha were validated as well (Figure 3, validation).

The MDADT method is an innovative unique method to capture land cover change in the form of buildings due to the following characteristics:

- Compared to existing land cover change methods, the MDADT Method uses only SAR data.

- This data is analysed in a freely available cloud from Google Earth Engine, Infrastructure as a Service.

- The MDADT method is very easy to program in the cloud.

- The result is used for long term civil land cover changes of buildings, not like other methods for oil spills, flood plains and vehicles etc.

- Compared to Che \& Gamba 2021 [62], the buildings are validated in the global north.

- In addition, this allows for multitemporal coverage of land cover changes over large areas and long time periods (see Figure 4). Thus, like the MDADT method, it can also be performed on an occasion-by-occasion basis.

- The validation of the results takes place with the help of freely available geospatial data (Section 2.2 Spatial Data).

- The results even allow a verification of the actual validation data.

- Furthermore, the very accurate results allow to show conclusions about the urban form and the validation data (Section 3 Results). 


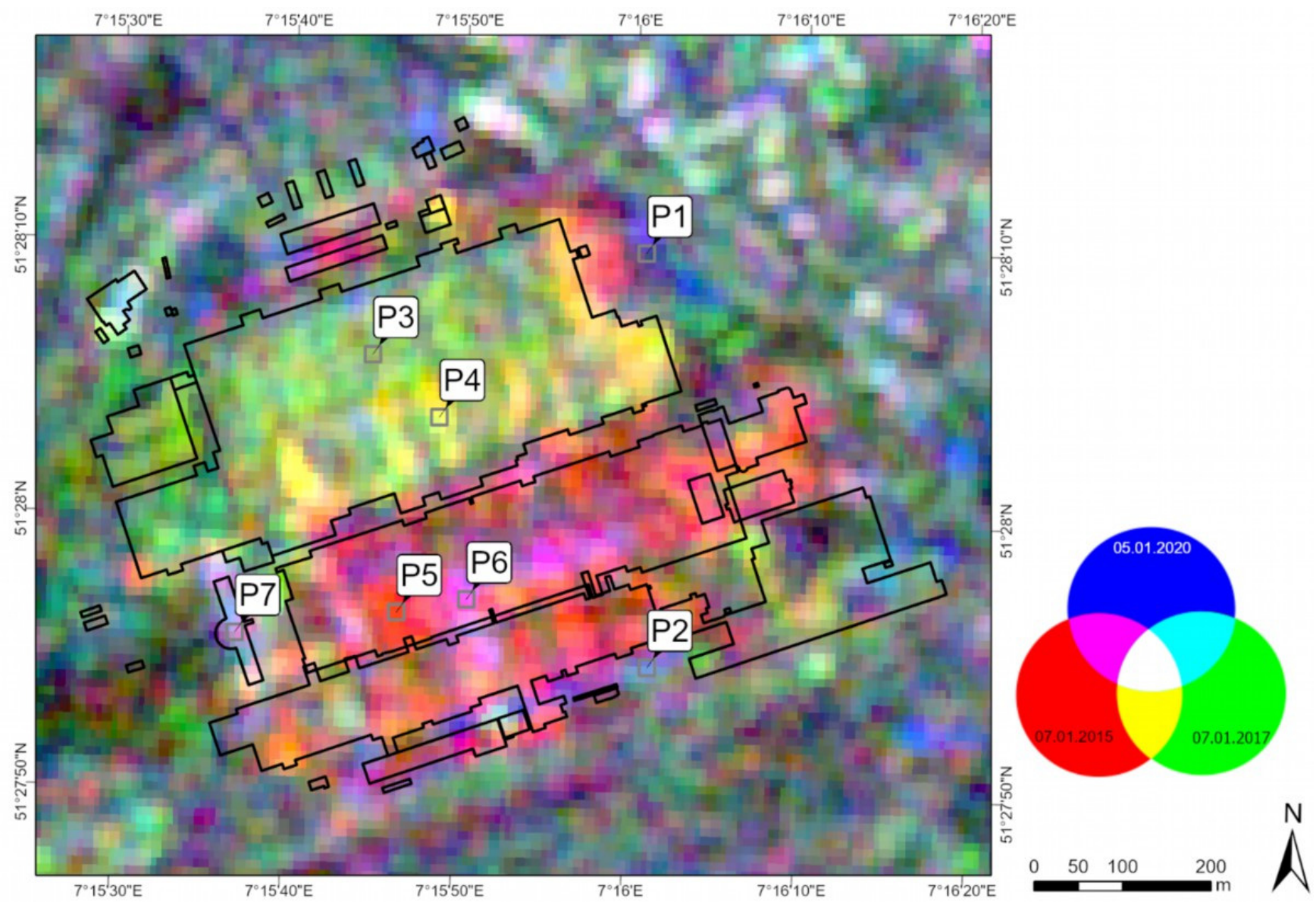

Figure 4. Multitemporal SAR representation of the former Opel plant I using an additive colour representation. The grey marked pixels represent the time of the respective land cover change, point one (P1) blue state 5 January 2020 in the eastern surroundings of the plant; P2 cyan change between 2017 and 2020 at the southern edge of the plant; P3 light green to cyan state 7 January 2017, former northern halls; P4 yellow change between 2015 and 2017, former central hall section; P5 red state 7 January 2015, former halls; P6 magenta change between 2015 and 2020, former southern halls; today DHL distribution centre. In this period, long-lasting land cover changes overlap; on the one hand factory halls were demolished, and on the other hand, the DHL distribution centre was built here afterwards. Here no already-depicted changes are shown, but only the difference between the first and the last image. P7 does not know of any changes to the still-existing administration building-today “O-Werk” [52,60].

\section{Results}

Using the MDADT method, land cover changes in the form of building demolitions and new buildings in Bochum, Germany were recorded. The additive colour mixture in Figure 4 shows impressively when the former Opelwerk I in Bochum was demolished. From this, the time periods of the demolition and the new construction of the DHL distribution centre can be determined.

A total of 21 land cover changes were extracted from the three radar images (Figure 5). Ten land cover changes can be verified as buildings by the house perimeters, which were newly built before. Of the remaining eleven land cover changes, two are taller buildings. One was demolished in the meantime and is thus no longer included in the house perimeter dataset, and the second building is not present in the house perimeter dataset at all. This building is a new university building, which itself is not yet included in the current house perimeter dataset. Another six land cover changes are new buildings that can only be explained by validation of current optical data. The remaining three changes result from 
sporadic backscatter of metal or already-demolished factory buildings or motor vehicles and temporary refugee housing.

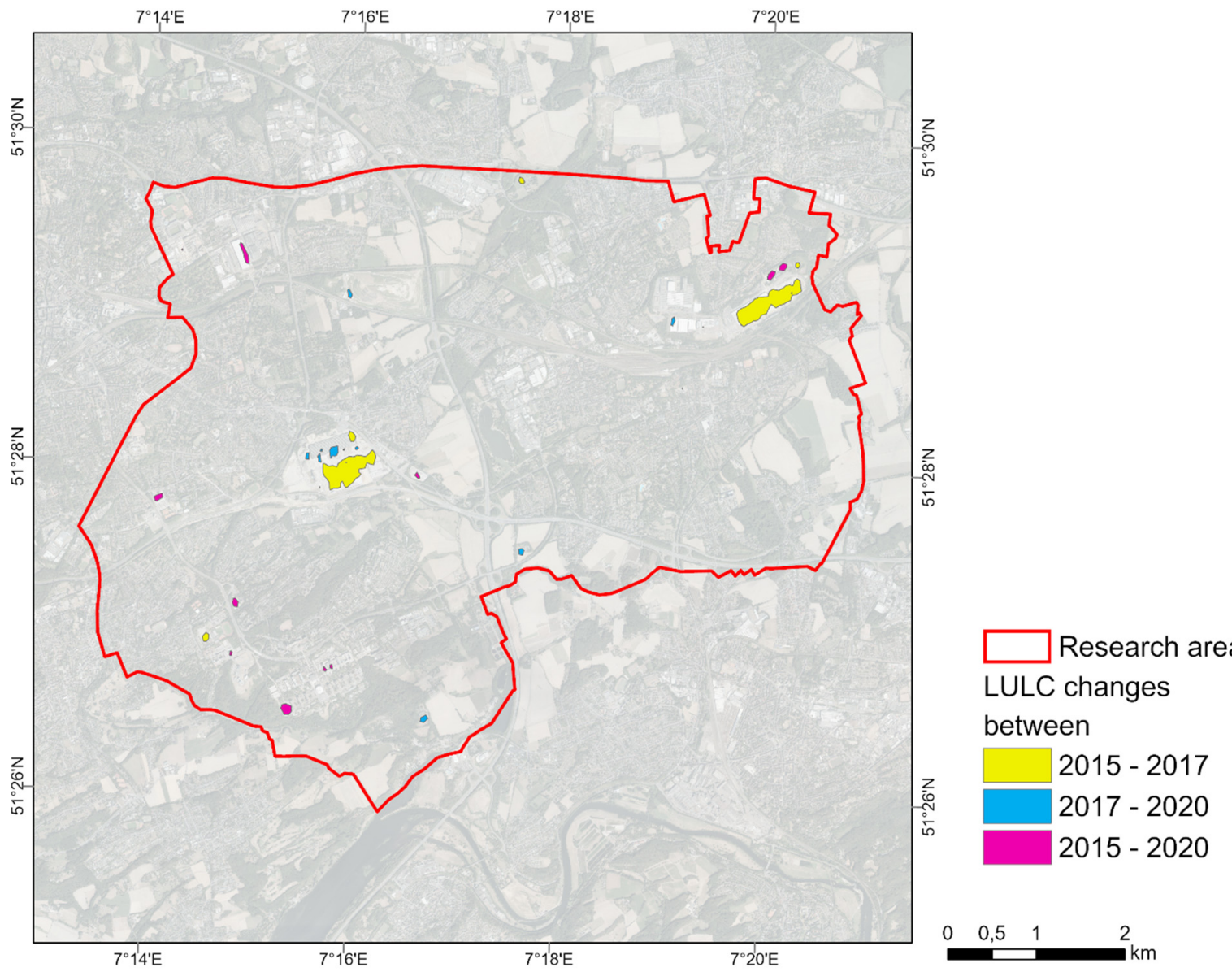

Figure 5. Recorded and validated multitemporal land cover changes between 2015, 2017, and $2020[49,52]$.

In an additional time series analysis of the data set of house perimeters between 2016 and 2021, the identical building demolitions and new buildings are shown (Figure 6). A few buildings are not captured by the MDADT method, e.g., because they were completed before the first recording in 2015 or were still under construction during the third and last recording in 2020 (Figure 7). This pattern corresponds to the characteristic life patterns of buildings [63].

Using the clip with the previously validated results of the MDADT method with the GUF data set, 23 land cover changes over $1000 \mathrm{~m}^{2}$ are now identified. The different number can be explained due to the coarser spatial resolution of the GUF dataset of $12 \times 7 \mathrm{~m}$ and the coarse subdivision into only two classes. Of these, the GUF data set presents nine as unsealed. For four this is true, for five they are sealed areas. In addition, 14 areas are built-up according to the GUF data set; for eight this is true, and for six it is a matter of unbuilt-up areas. 


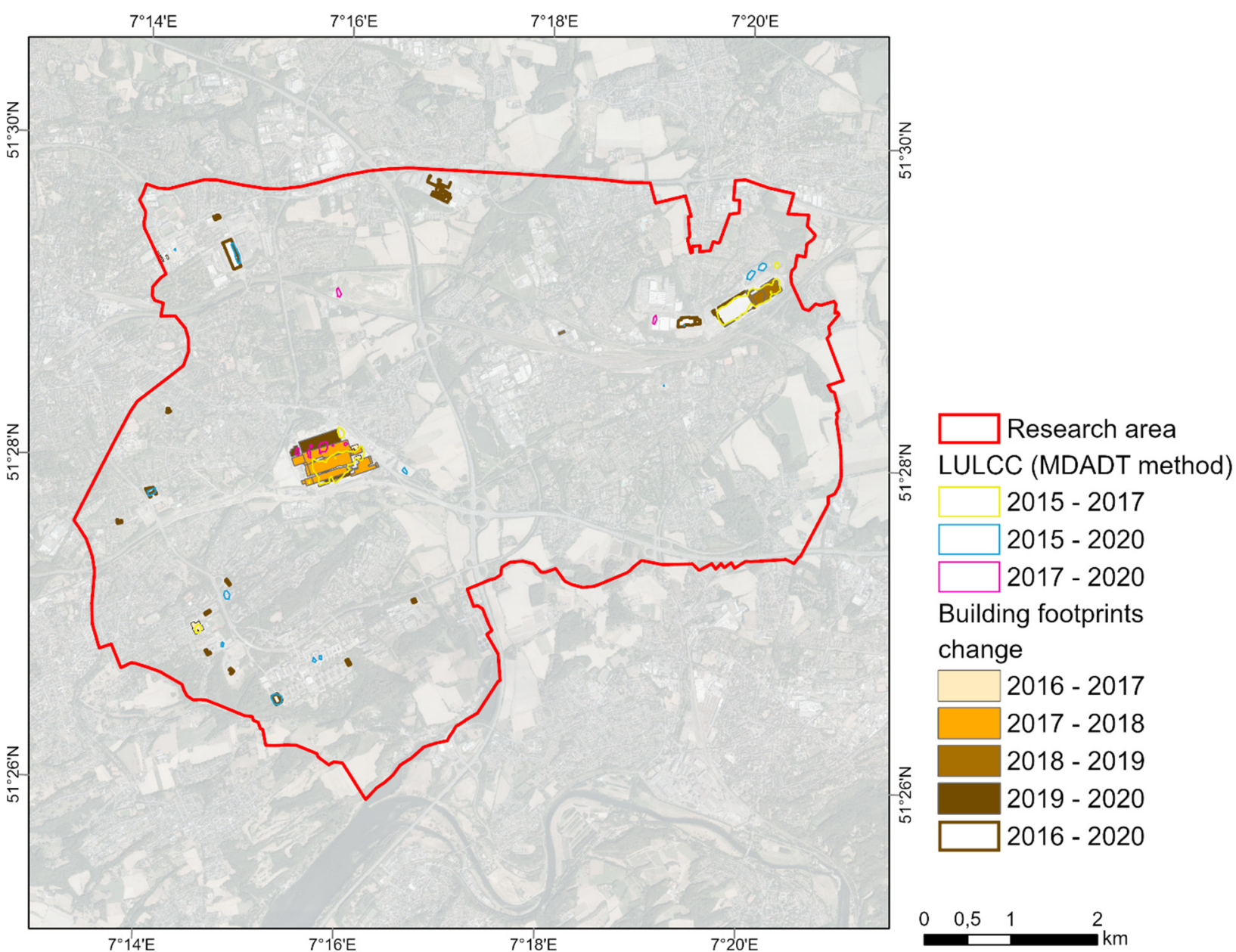

Figure 6. Composite changes in the house perimeter dataset from 2016 to 2021 compared to the results of the MDADT method's recorded land cover changes in yellow (2015-2017), cyan (2017-2020) and magenta (2015-2020) [49,52].

The GUF dataset can be used to roughly categorize unsealed and sealed areas. Due to this simple categorization, it is only partially useful for validating land cover changes. It can rather serve as a reference for similar analyses.

Comparing the WSF 2015 and WSF 2019 datasets, 22 land cover changes larger than $1000 \mathrm{~m}^{2}$ can be identified. Again, the different number can be explained based on the coarser spatial resolution of the WSF dataset of $10 \times 6 \mathrm{~m}$ and the coarse subdivision into only two classes. Three of them coincide with the changes recorded here by the MDADT method. Another nine can be explained by the house perimeters. In terms of height, none of the remaining 10 can be identified as buildings. With optical data, these can be identified as metallic objects on construction sites.

In the previously described validations with public high-resolution third-party geospatial data (Table 2), the results could be verified very well. In an additional check with respect to the validity or accuracy of the land cover changes captured by the MDADT method in the respective time periods, it can be seen that the majority are "True positive", i.e., really a building has been newly constructed, e.g., between 2015 and 2020 (Table 3, Figures 8 and 9). A few are "True negative", because a large building was demolished in the same place and then a new smaller building was erected. The remaining area of the former larger building is no longer used by a new building, but is brownfield. 


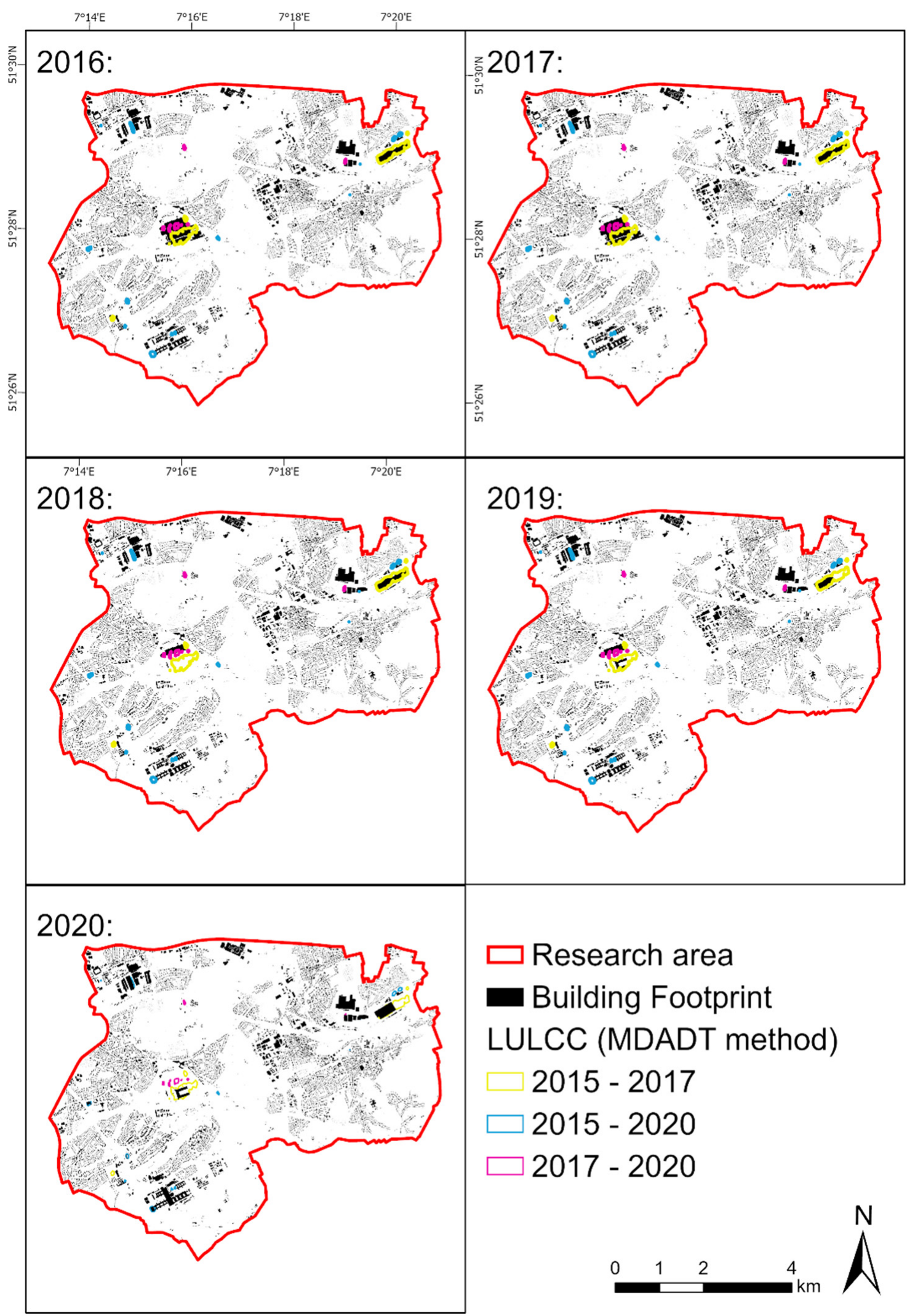

Figure 7. Changes in the house perimeter dataset per year from 2016-2020, compared to the results of the MDADT method's recorded land cover changes $[52,53]$. 
Table 3. Overview of the accuracy of the land cover changes recorded and validated by the MDADT method in the respective time periods [52].

\begin{tabular}{|c|c|c|c|c|c|c|c|c|c|c|c|}
\hline & \multicolumn{2}{|c|}{ Constructed } & \multicolumn{2}{|c|}{$\begin{array}{l}\text { Constructed- } \\
\text { Deconstructed }\end{array}$} & \multicolumn{2}{|c|}{ Deconstructed } & \multicolumn{2}{|c|}{$\begin{array}{l}\text { Deconstructed- } \\
\text { Constructed }\end{array}$} & \multicolumn{2}{|c|}{ Metal } & \multirow{2}{*}{ Sum } \\
\hline & $\begin{array}{c}\text { True } \\
\text { Positive }\end{array}$ & $\begin{array}{c}\text { True } \\
\text { Negative }\end{array}$ & $\begin{array}{c}\text { True } \\
\text { Positive }\end{array}$ & $\begin{array}{c}\text { True } \\
\text { Negative }\end{array}$ & $\begin{array}{c}\text { True } \\
\text { Positive }\end{array}$ & $\begin{array}{c}\text { True } \\
\text { Negative }\end{array}$ & $\begin{array}{c}\text { True } \\
\text { Positive }\end{array}$ & $\begin{array}{c}\text { True } \\
\text { Negative }\end{array}$ & $\begin{array}{c}\text { True } \\
\text { Positive }\end{array}$ & $\begin{array}{c}\text { True } \\
\text { Negative }\end{array}$ & \\
\hline 2015-2017 & & & & & 3 & & 1 & 1 & & & 5 \\
\hline 2015-2020 & 9 & & 1 & & & & & & 1 & & 11 \\
\hline $2017-2020$ & 1 & & 1 & & 1 & & & & 2 & & 5 \\
\hline sum & 10 & 0 & 2 & 0 & 4 & 0 & 1 & 1 & 3 & 0 & 21 \\
\hline
\end{tabular}

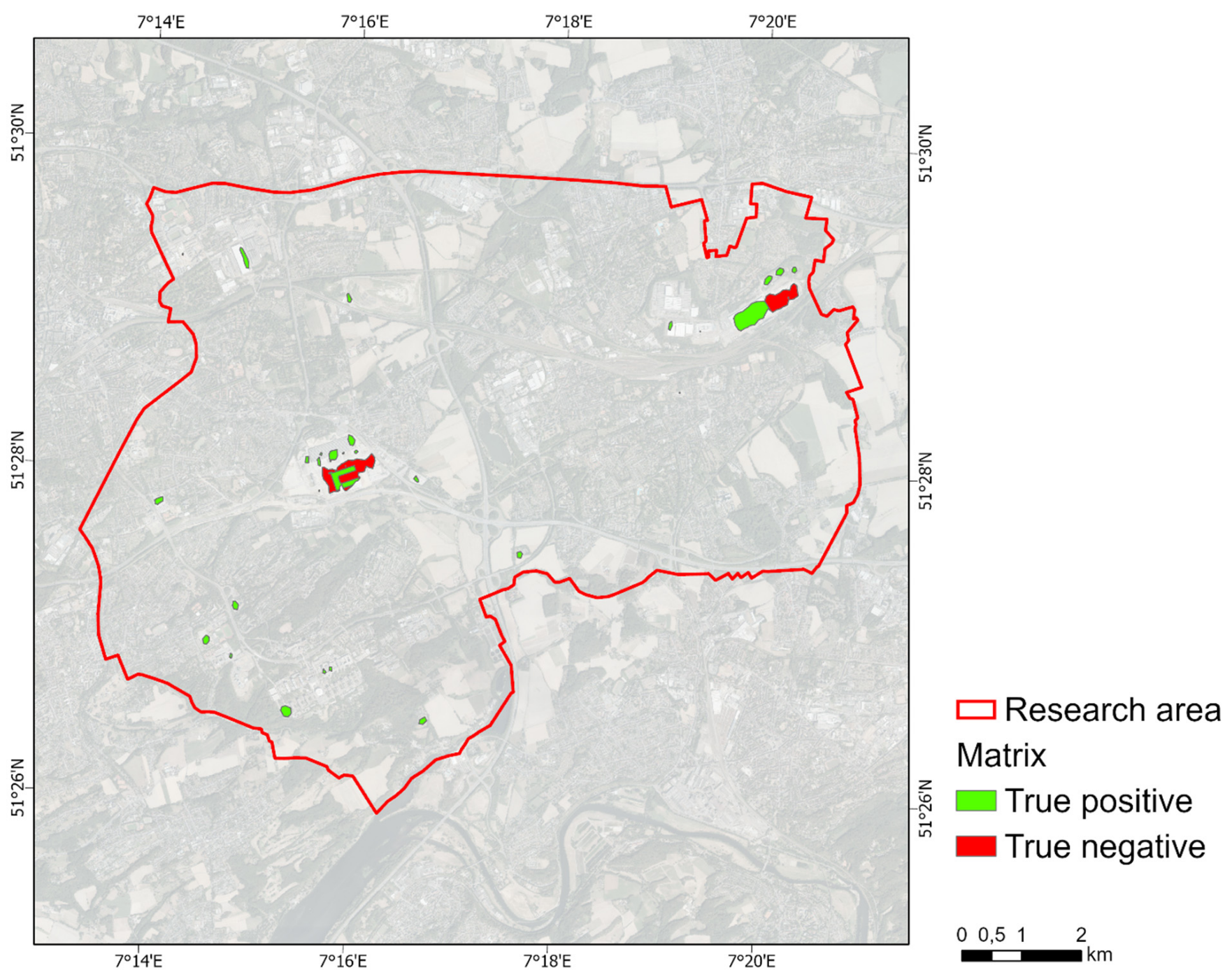

Figure 8. Accuracy of land cover changes recorded and validated by the MDADT method [49,52].

In relation to the different categories of urban form studied, it can be noted that under the category of materials human constructs like building demolitions and new buildings can be well identified in the form of land cover changes of urban form. A majority of buildings were constructed in the period of 2015-2020 (Table 4, Figure 10). Three land cover changes represent building demolitions between 2015 and 2017. In the configuration category, two-dimensional changes and distribution of spatial patterns were recorded in terms of their spatial extent of urban form (Figure 10). 


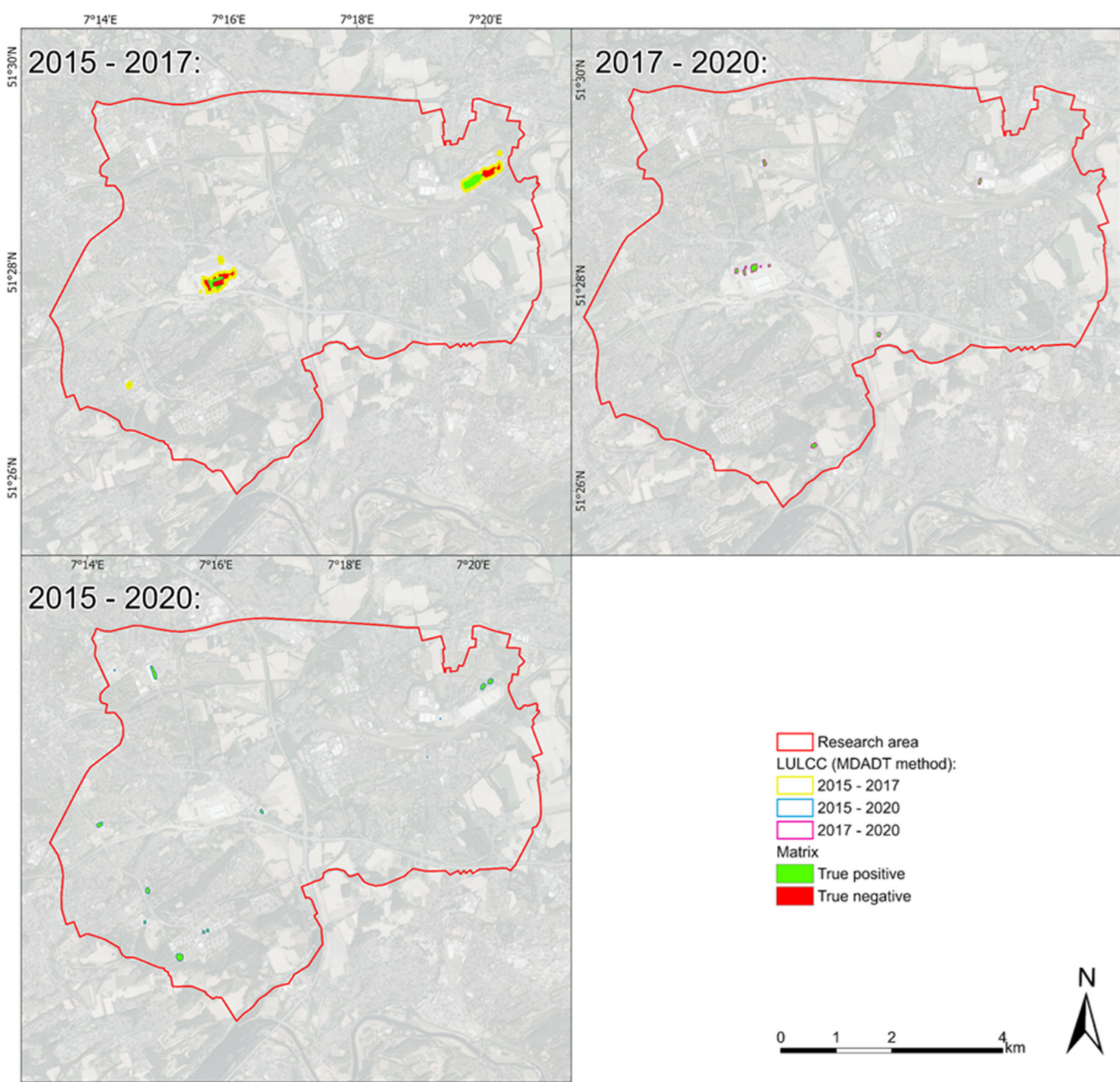

Figure 9. Accuracy of land cover changes recorded and validated by the MDADT method in the respective time periods $[49,52]$.

Table 4. Overview of land cover change recorded by the MDADT method in relation to the type of change [52].

\begin{tabular}{ccccccc}
\hline & Constructed & $\begin{array}{c}\text { Constructed- } \\
\text { Deconstructed }\end{array}$ & Deconstructed & $\begin{array}{c}\text { Deconstructed- } \\
\text { Constructed }\end{array}$ & Metal & Sum \\
\hline $2015-2017$ & 9 & 1 & 3 & 2 & 5 & 11 \\
$2015-2020$ & 1 & 1 & 1 & & 2 & 5 \\
$2017-2020$ & 10 & 2 & 4 & 2 & 3 & 21 \\
\hline sum & & & & & 3 \\
\hline
\end{tabular}




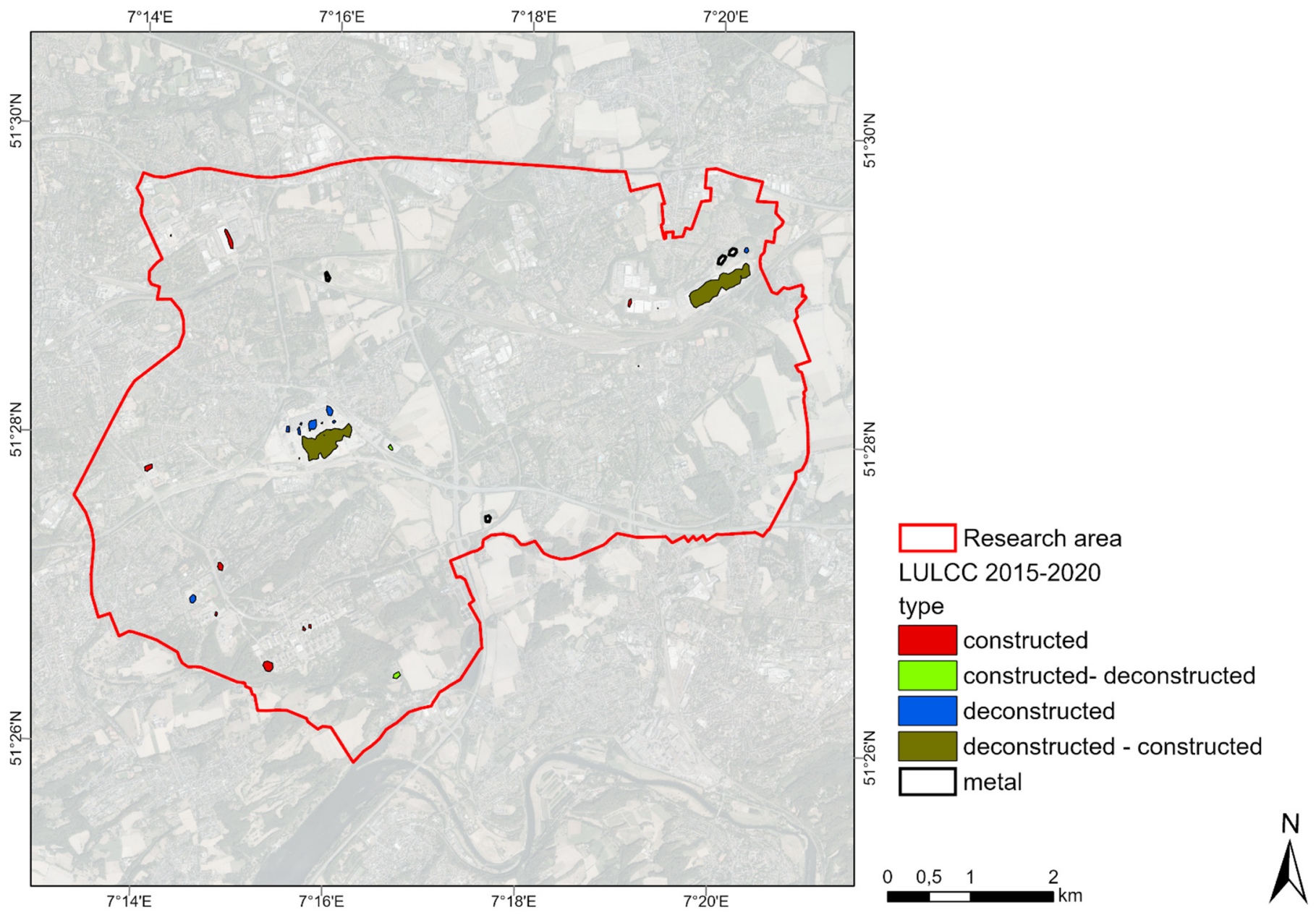

Figure 10. Recorded and validated multitemporal land cover changes between the years 2015, 2017, and 2020 of the MDADT method in terms of land cover change type $[49,52]$.

On some medium-sized areas (0.1-1 ha), buildings were erected or dismantled, e.g., between 2015-2020 (Table 5, Figure 11). Only half as many large sites are affected.

Table 5. Overview of land cover changes detected by the MDADT method in relation to its spatial extent [52].

\begin{tabular}{ccccc}
\hline & Large & Middle & Small & Sum \\
\hline $2015-2017$ & 2 & 3 & 3 & 5 \\
$2015-2020$ & 2 & 6 & & 11 \\
$2017-2020$ & 1 & 4 & 3 & 5 \\
\hline sum & 5 & 13 & 21 \\
\hline
\end{tabular}

In the comparison of the investigated aspects of urban form, it is noticeable that more buildings were newly erected than demolished (Table 6). In some large areas ( $>1$ ha) different changes took place. In small areas $(<0.1 \mathrm{ha})$, new buildings were erected. From these results, it can be concluded that structural change leads to only some large-scale changes, but to a large number of changes in medium-scale areas. The category time/dynamics and its temporal aspect allows to present a time series analysis of land cover changes. 


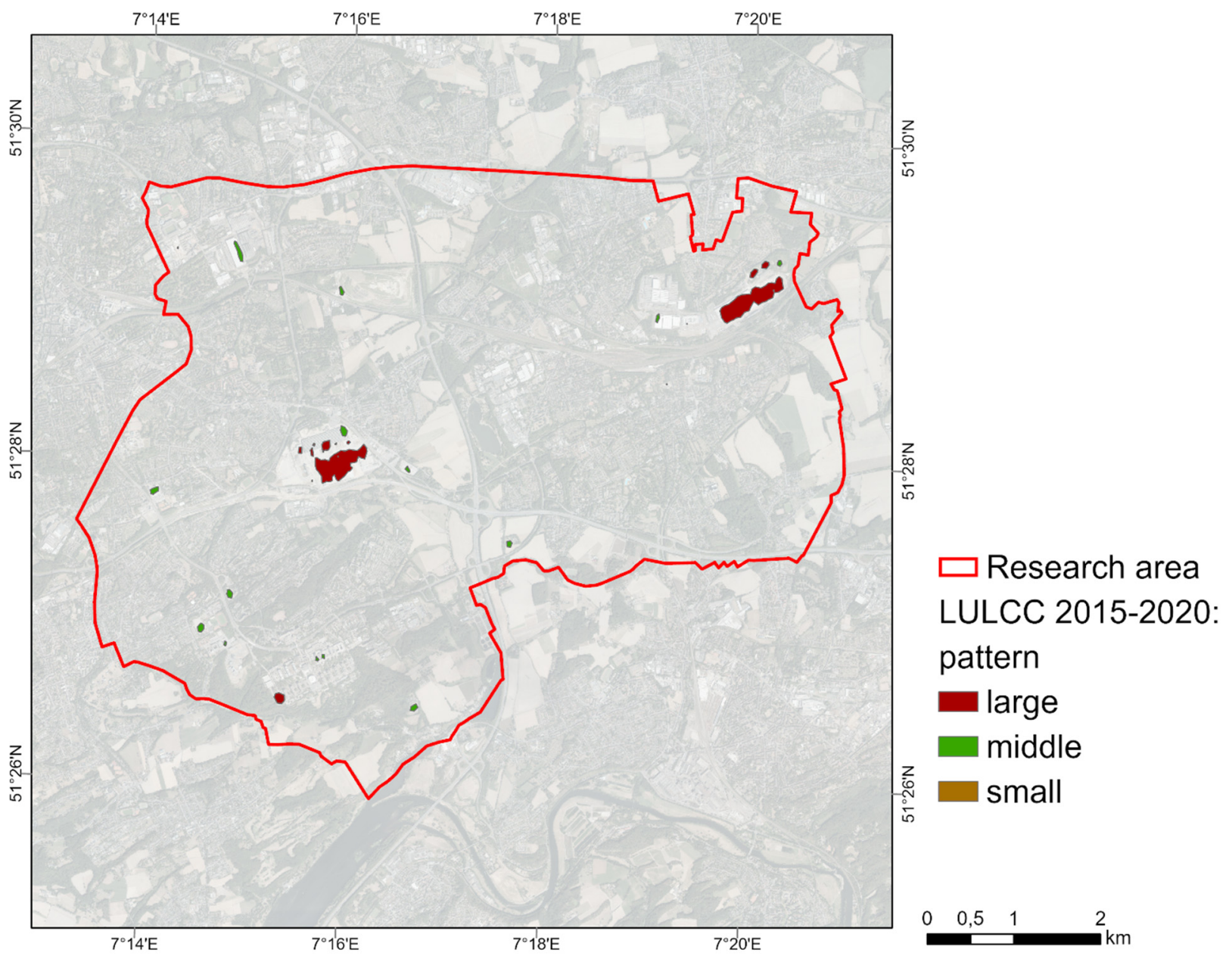

Figure 11. Land cover changes detected by the MDADT method between 2015 and 2020 shown in their spatial extent: large ( $>1 \mathrm{ha})$, middle $(0.1-1 \mathrm{ha})$ and small $(<0.1 \mathrm{ha})[49,52]$.

Table 6. Overview of land cover changes detected by the MDADT method in relation to its type of change and spatial extent [52].

\begin{tabular}{cccccc}
\hline $\begin{array}{c}\text { Pattern } \\
\text { (Area) } \backslash \text { Type }\end{array}$ & Constructed & Deconstructed & $\begin{array}{c}\text { Deconstructed- } \\
\text { Constructed }\end{array}$ & Metal & Sum \\
\hline large & 1 & 1 & 2 & 1 & 5 \\
middle & 8 & 3 & 0 & 2 & 13 \\
small & 3 & 0 & 0 & 0 & 3 \\
\hline sum & 12 & 4 & 2 & 3 & 21 \\
\hline
\end{tabular}

In comparison, the globally available GUF and WSF data are less clear in identifying land cover changes (Figure 12). 


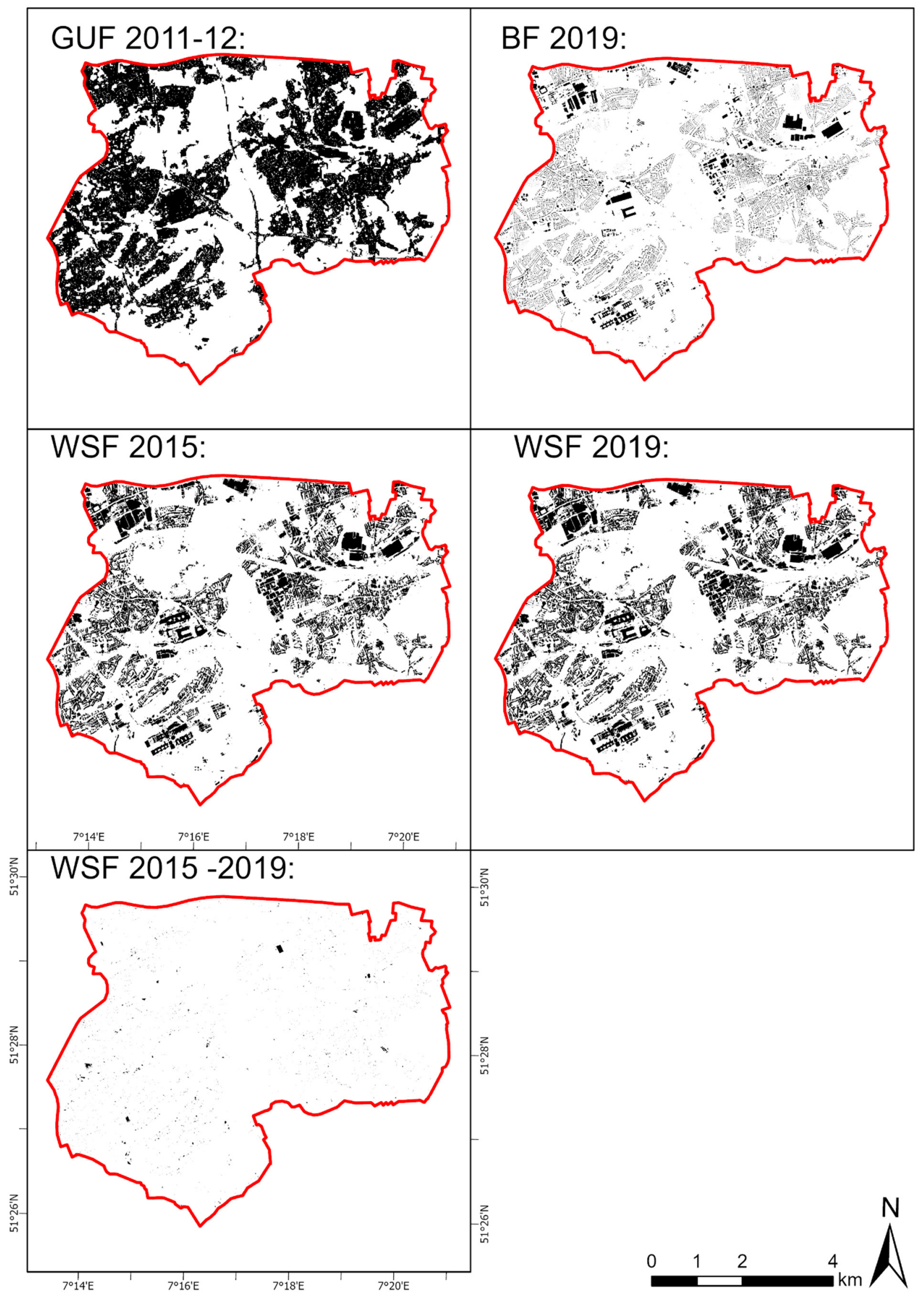

Figure 12. Comparison of the 2011-12 GUF, 2015 \& 2019 WSF datasets and their changes compared to the 2019 house perimeters $[53,57,59,61]$. 


\section{Discussion}

Land cover changes can be well identified by this SAR-based MDADT method. These land cover changes in the form of building demolitions and new buildings represent a change in urban form. Thus, land cover changes can be analysed multitemporally at three time points for an extended period of time. This is in contrast to the REACTIV method, which can better identify land cover changes for specific events (Figure 13) [64].

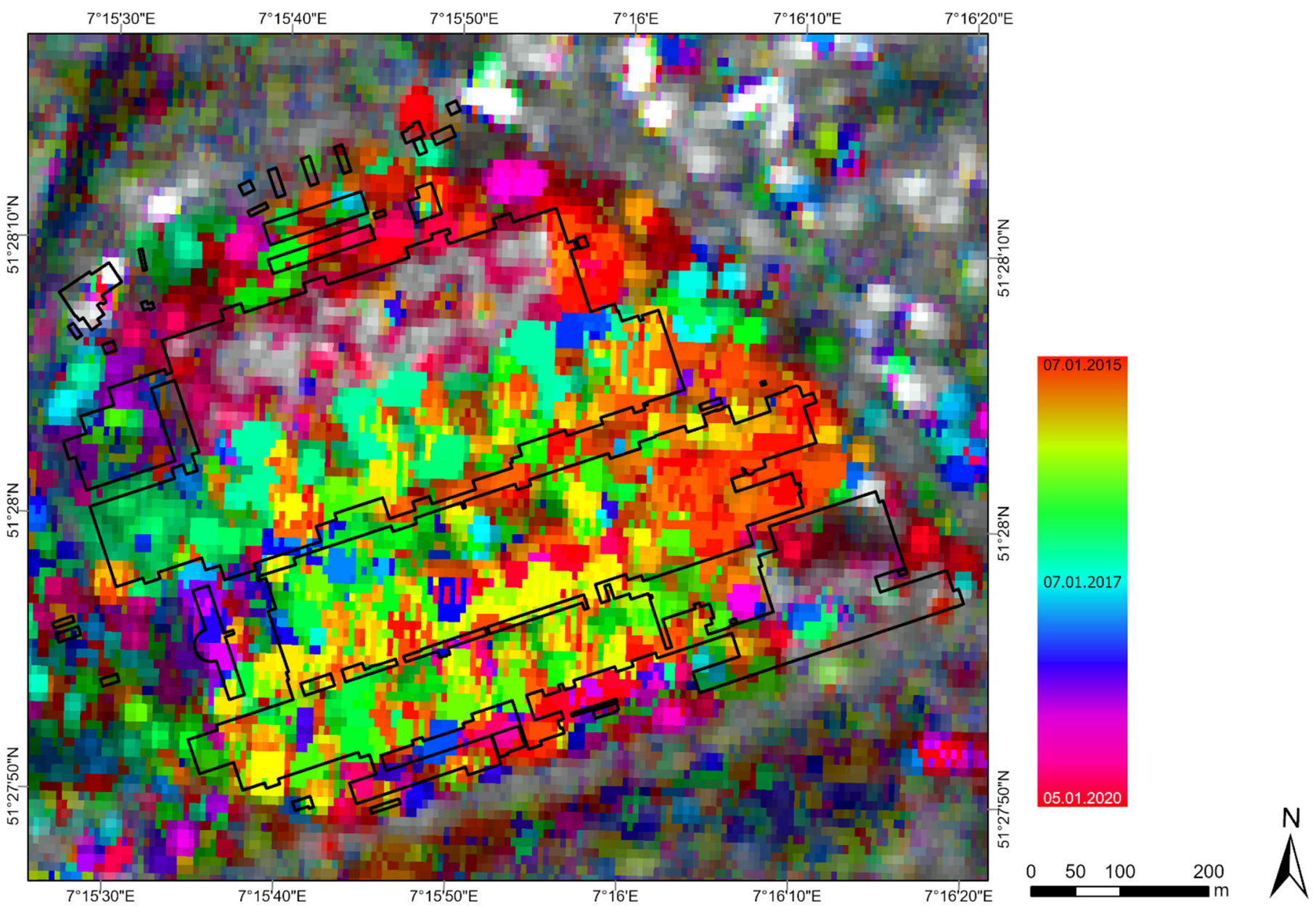

Figure 13. Multitemporal SAR representation of the former Opel plant I using the REACTIV method in HSV colour space; see Figure 4 in comparison in the RGB colour space. Land cover changes from 7 January 2015 are shown in light red, e.g., in the eastern part of the former Opel plant. Land cover changes around 7 January 2017 are marked in blue-cyan. Changes until 5 January 2020 are shown in dark red, e.g., southern surroundings of Opelwerk [64,65].

With the REACTIV method, changes in land cover can be represented in a short period of time. Thus, spatially explicit short-term changes can be represented differently than in the treated study area period. Also the exact date or period of the change cannot be derived so easily in contrast to the additive representation in the RGB colour space. In addition, there is a noise floor in the image that makes it difficult to identify smaller changes.

It overestimates land cover changes due to different backscatter [40]. The analysis presented here is good at identifying building demolitions and new construction. Moreover, this also reveals weaknesses from the actual third-party geospatial data. For example, the IA and IB buildings of the Ruhr University Bochum are not represented in the current house perimeter dataset, even though they have existed since mid-2018. This would be a use case for this MDADT method. However, the authority responsible for this also accepts improvement hints in the context of crowdsourcing [66]. 
The already existing Landscape Change Service (LaVerDi) of the Federal Agency for Cartography and Geodesy uses only optical data; see detail in Table 7. Thus, SAR properties are not considered and land cover changes in the form of buildings are underestimated.

Table 7. Overview of the properties of LaVerDi.

\begin{tabular}{|c|c|}
\hline Specifications $\backslash$ Data & LaVerDi \\
\hline Coverage & Germany \\
\hline Spatial resolution & $>0.5 \mathrm{ha}$ \\
\hline Temporal reference & 2020 \\
\hline Output data & $\begin{array}{l}\text { LULCC digital Land Cover } \\
\text { Model Germany (LBM-DE) and sentinel-2 }\end{array}$ \\
\hline $\begin{array}{l}\text { Position projection-Reference System } \\
\text { EPSG }\end{array}$ & 4258 \\
\hline $\begin{array}{c}\text { Height projection- } \\
\text { Reference System } \\
\text { EPSG }\end{array}$ & / \\
\hline Data format & SHP \\
\hline Typology/Class/Attribute & $\begin{array}{c}\text { Confidence, Land use land cover; probability } \\
\text { of change, method, Area }\end{array}$ \\
\hline Version & / \\
\hline $\begin{array}{l}\text { Geometric resolution } \\
\text { Scale }\end{array}$ & / \\
\hline Thematic accuracy & $>80$ \\
\hline Production time & 2020 \\
\hline Accessibility & Open data \\
\hline License & not required \\
\hline Source-Responsible organisation & BKG \\
\hline Reference & {$[67-69]$} \\
\hline
\end{tabular}

LaVerDi shows, in part, only changes in vegetation and ground surface for the years 2018-2019 in the study area used here [68]. It only fails to capture new construction represented by the analysis presented here (Figure 14). In addition, LaVerDi also makes statements about the reliability of the recorded land cover change. In the investigated area it is only highest at the former Opel plant I, in the other cases it is not very reliable.

The GUF data do a poor job of identifying land cover changes because they only roughly detect anthropogenically influenced areas. In addition, the GUF creation date does not match the study period used here. Nevertheless, conclusions can be drawn about the informative value of the GUF dataset. Chini et al., 2018 also notes that the GUF dataset overestimates built-up areas and, in addition, sealed areas or parking lots are sometimes represented as urban [70]. In addition, a regular new edition as already done with the WSF dataset would be desirable.

With the WSF, the level of detail has already been improved. Therefore, both datasets provide a rough identifier of land sealing.

An important criterion in the analysis presented here is the choice of the time points or length of the period between the images. This has a significant influence on whether or not land cover change can be detected. A mask is created by extracting the values above ten and minus ten from the ratio between exposures. Specifically, in the first period, no land cover change is identified, in the second the change occurs, and in the third period, it is already absent. In the specific case, for example, it is a temporary land cover change that is only present in one image. This is only present for too short a time to identify it with the land cover change analysis presented here.

Therefore, only permanent land cover changes in the study area during this period can be analysed. Overall, permanent land cover changes of urban form in the form of building demolition and new construction can be well captured by this SAR-based MDADT method. 


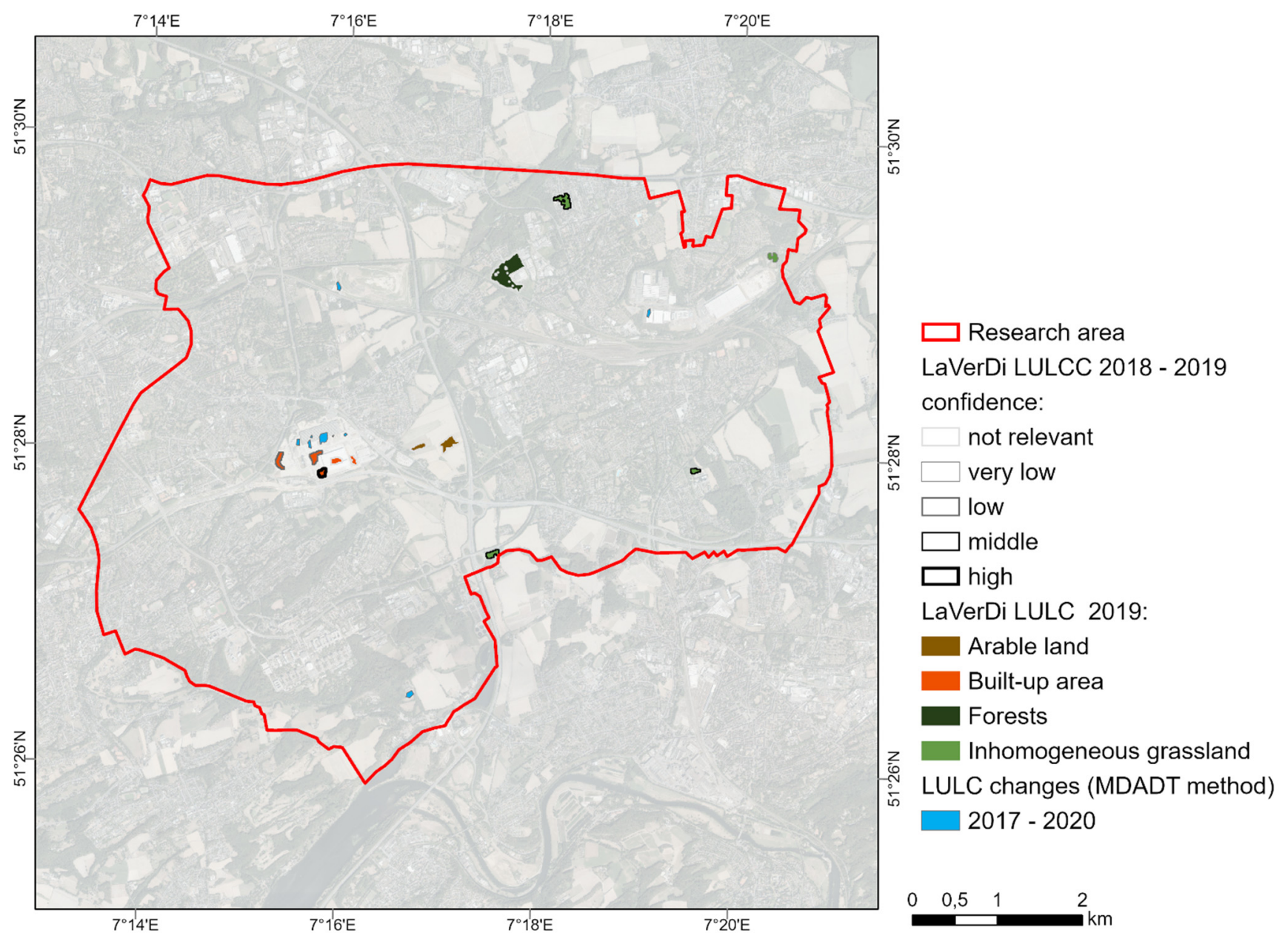

Figure 14. LaVerDi land cover changes between 2018-2019 compared to MDADT method land cover changes between 2017-2020 [49,52,68].

\section{Conclusions}

With this SAR-based study, land cover changes such as building demolitions and new buildings can be recorded over a period of several years.

After the initial run of the workflows described in Section 2.3, Methodology, too many land cover changes were recorded. This could be reduced by choosing January images.

Subsequently, the different backscatter generated more land cover changes. This problem could be solved by selecting a filter $>10$ for buildings. Since the focus of this study is on long term land cover changes in the form of sealing by buildings in the study area, this filter turns out to be very suitable.

This left a few lands cover changes that could be explained by SAR interaction with metallic objects in the validation. These could be easily categorized in the validation with partly high-resolution third-party data. The validation shows also weaknesses of these public high resolution geospatial data. The land cover changes of the urban form show densities in the urban space. No land cover changes in the form of new buildings in the open space were recorded.

This can be applied, for example, in a city administration that wants to check its previous functional zoning or green space planning by analysing whether urban sprawl has been reduced and whether planned urban consolidation has taken place.

Furthermore, the responsible geospatial data authority, for example, can check and update its data timeliness. In addition, it can also be determined whether land cover changes have occurred in areas that are protected -worthy of protection. 
The processes of structural change in the vicinity of urban renewal areas, such as those caused by the demolition of Opelwerk I and II and the economic reorientation caused by new buildings, can be well recorded.

Also, on the one hand, the consequences of migration can be seen through the construction of temporary refugee accommodations and, on the other hand, structural change through tertiarization, such as through the construction of a new university building and student dormitories. In contrast, this land cover change analysis cannot capture short-term land cover changes as with the REACTIVE method.

This study presented here allows the detection of large-scale permanent land cover changes over a long period of time. The importance of this study lies in the recording of the progressive urban sprawl in urban areas. Natural areas are often destroyed by development. A natural resilient habitat becomes vulnerable to extreme events. To capture this in urban areas, SAR data with a high recurrence rate are particularly suitable. They can capture land cover changes quickly, easily, and straightforwardly. So far, only passive data is often used in land cover change analyses, but they depend on cloud cover.

This argument also leads to the novelty of this study because it uses only SAR data and can be easily implemented globally. It also provides an opportunity to review and or update existing data. Previous similar studies do not focus on medium-term civil use cases. In addition, this study uses open data from Sentinel-1 and is Cloud Infrastructure as a Service based. The land cover changes captured can be applied multitemporally, over large areas, and accurately indicate the time period of land cover changes. These results can be used to represent and describe processes of urban form.

In addition, the validation with also freely available data showed high accuracy. Thus, land cover changes of large-scale industrial areas in the global north could be identified.

This study could also be applied to other areas without any problems. To exclude the interaction of SAR waves with rain or puddles, however, weather data are necessary.

Furthermore, existing house perimeter data can facilitate the interpretation of the results. In addition, however, it should be noted that the respective urban form can significantly complicate the transferability.

This is because in very small-scale parcelled heterogeneous urban forms, such as slums or old city centres, the recording of land cover changes becomes more difficult. This contrasts with large-scale homogeneous urban forms such as planned housing developments or industrial facilities.

This hindrance can be explained due to the backscatter of SAR waves and the spatial resolution of Sentinel-1. Thus, all possible land cover changes at the bottom within $10 \times 10 \mathrm{~m}$ are averaged. Therefore, no land cover changes smaller than $100 \mathrm{~m}^{2}$ can be detected. Due to these sensor properties of Sentinel-1, this study can only detect medium-term land cover changes in the form of buildings in large homogeneous areas.

Author Contributions: Conceptualization, L.G. and C.J.; methodology, L.G.; validation, L.G. and C.J.; formal analysis, L.G.; investigation, L.G.; resources, L.G.; data curation, L.G.; writing-original draft preparation, L.G. and C.J.; writing-review and editing, C.J. and L.G.; visualization, L.G. and C.J.; supervision, C.J.; project administration, C.J.; funding acquisition, C.J. All authors have read and agreed to the published version of the manuscript.

Funding: This research was funded by the German Federal Ministry of Education and Research (Bundesministerium für Bildung und Forschung, BMBF), grant number 01LE1805A1.

Institutional Review Board Statement: Not applicable.

Informed Consent Statement: Not applicable.

Conflicts of Interest: The authors declare no conflict of interest. 


\section{References}

1. Mumford, L. The Natural History of Urbanization The Emergence of the City. Man's Role Chang. Face Earth 1956, 1, $382-398$.

2. Bairoch, P. Cities and Economic Development: From the Dawn of History to the Present, 2nd ed.; University of Chicago Press: Chicago, IL, USA, 1988.

3. Anderson, W.P.; Kanaroglou, P.S.; Miller, E.J. Urban Form, Energy and the Environment: A Review of Issues, Evidence and Policy. Urban Stud. 1996, 33, 7-35. [CrossRef]

4. Rodrigue, J.P.; Comtois, C.; Slack, B. The Geography of Transport Systems, 3rd ed.; Routledge: Oxon, UK, 2013; ISBN 9781317210108.

5. Dempsey, N.; Brown, C.; Raman, S.; Porta, S.; Jenks, M.; Jones, C.; Bramley, G. Elements of Urban Form. In Dimensions of the Sustainable City; Springer: Dordrecht, The Netherlands, 2010; pp. 21-51.

6. Dieleman, F.; Wegener, M. Compact City and Urban Sprawl. Built Environ. 2004, 30, 308-323. [CrossRef]

7. Frank, L.D.; Engelke, P.O. The Built Environment and Human Activity Patterns: Exploring the Impacts of Urban Form on Public Health. J. Plan. Lit. 2001, 16, 202-218. [CrossRef]

8. Dempsey, N.; Brown, C.; Bramley, G. The Key to Sustainable Urban Development in UK Cities? The Influence of Density on Social Sustainability. Prog. Plan. 2012, 77, 89-141. [CrossRef]

9. Batty, M. The New Science of Cities; The MIT Press: Cambridge, UK, 2013.

10. Wentz, E.A.; York, A.M.; Alberti, M.; Conrow, L.; Fischer, H.; Inostroza, L.; Jantz, C.; Pickett, S.T.A.; Seto, K.C.; Taubenböck, H. Six Fundamental Aspects for Conceptualizing Multidimensional Urban Form: A Spatial Mapping Perspective. Landsc. Urban Plan. 2018, 179, 55-62. [CrossRef]

11. Rashed, T.; Jürgens, C. Remote Sensing of Urban and Suburban Areas; Springer: Dordrecht, The Netherlands, 2010.

12. Netzband, M.; Jürgens, C. Urban and Suburban Areas as a Research Topic for Remote Sensing. In Remote Sensing and Digital Image Processing; Rashed, T., Jürgens, C., Eds.; Springer: Dordrecht, The Netherlands, 2010; Volume 10, pp. 1-9.

13. Jürgens, C. Change Detection-Erfahrungen Bei Der Vergleichenden Multitemporalen Satellitenbildauswertung in Mitteleuropa. Photogramm. Fernerkund. Geoinf. (PFG) 2000, 1, 5-18.

14. Pohl, C.; van Genderen, J.L. Review Article Multisensor Image Fusion in Remote Sensing: Concepts, Methods and Applications; Taylor \& Francis: London, UK, 1998; Volume 19, ISBN 0143116982157.

15. Notti, D.; Giordan, D.; Caló, F.; Pepe, A.; Zucca, F.; Galve, J.P. Potential and Limitations of Open Satellite Data for Flood Mapping. Remote Sens. 2018, 10, 1673. [CrossRef]

16. Ferretti, A.; Prati, C.; Rocca, F. Permanent Scatterers in SAR Interferometry. IEEE Trans. Geosci. Remote Sens. 2001, 39, 8-20. [CrossRef]

17. Koeniguer, E.C.; Nicolas, J.M. Change Detection Based on the Coefficient of Variation in SAR Time-Series of Urban Areas. Remote Sens. 2020, 12, 2089. [CrossRef]

18. Amitrano, D.; di Martino, G.; Iodice, A.; Riccio, D.; Ruello, G. Small Reservoirs Extraction in Semiarid Regions Using Multitemporal Synthetic Aperture Radar Images. IEEE J. Sel. Top. Appl. Earth Obs. Remote Sens. 2017, 10, 3482-3492. [CrossRef]

19. Brunner, D.; Lemoine, G.; Bruzzone, L. Earthquake Damage Assessment of Buildings Using VHR Optical and SAR Imagery. IEEE Trans. Geosci. Remote Sens. 2010, 48, 2403-2420. [CrossRef]

20. Cian, F.; Marconcini, M.; Ceccato, P. Normalized Difference Flood Index for Rapid Flood Mapping: Taking Advantage of EO Big Data. Remote Sens. Environ. 2018, 209, 712-730. [CrossRef]

21. Reiche, J.; Verbesselt, J.; Hoekman, D.; Herold, M. Fusing Landsat and SAR Time Series to Detect Deforestation in the Tropics. Remote Sens. 2015, 156, 276-293. [CrossRef]

22. Kellndorfer, J. SAR Training Workshop for Forest Applications Part 1-Getting to Know SAR Images and Forest Signatures Software Installation and Data Sets Importing Relevant Python Packages; SERVIR Global Science Coordination Office, National Space Science and Technology Center: Huntsville, AL, USA, 2019; ISBN 1920151117.

23. Inglacla, J.; Mercier, G. A New Statistical Similarity Measure for Change Detection in Multitemporal SAR Images and Its Extension to Multiscale Change Analysis. IEEE Trans. Geosci. Remote Sens. 2007, 45, 1432-1445. [CrossRef]

24. Amitrano, D.; di Martino, G.; Guida, R.; Iervolino, P.; Iodice, A.; Papa, M.N.; Riccio, D.; Ruello, G. Earth Environmental Monitoring Using Multi-Temporal Synthetic Aperture Radar: A Critical Review of Selected Applications. Remote Sens. 2021, 13, 604. [CrossRef]

25. Quin, G.; Pinel-Puyssegur, B.; Nicolas, J.M.; Loreaux, P. MIMOSA: An Automatic Change Detection Method for Sar Time Series. IEEE Trans. Geosci. Remote Sens. 2014, 52, 5349-5363. [CrossRef]

26. Coombs, W.T.; Algina, J.; Oltman, D.O. Univariate and Multivariate Omnibus Hypothesis Tests Selected to Control Type I Error Rates When Population Variances Are Not Necessarily Equal. Rev. Educ. Res. 1996, 66, 137-179. [CrossRef]

27. Conradsen, K.; Nielsen, A.A.; Skriver, H. Determining the Points of Change in Time Series of Polarimetric SAR Data. IEEE Trans. Geosci. Remote Sens. 2016, 54, 3007-3024. [CrossRef]

28. Rutkowski, J.; Canty, M.J.; Nielsen, A.A. Topical Papers Site Monitoring with Sentinel-1 Dual Polarization SAR Imagery Using Google Earth Engine. J. Nucl. Mater. Manag. 2018, XLVI, 48-59.

29. Muro, J.; Strauch, A.; Fitoka, E.; Tompoulidou, M.; Thonfeld, F. Mapping Wetland Dynamics with SAR-Based Change Detection in the Cloud. IEEE Geosci. Remote Sens. Lett. 2019, 16, 1536-1539. [CrossRef]

30. Li, Y.; Martinis, S.; Wieland, M.; Schlaffer, S.; Natsuaki, R. Urban Flood Mapping Using SAR Intensity and Interferometric Coherence via Bayesian Network Fusion. Remote Sens. 2019, 11, 2231. [CrossRef] 
31. D'Addabbo, A.; Refice, A.; Pasquariello, G.; Lovergine, F.P.; Capolongo, D.; Manfreda, S. A Bayesian Network for Flood Detection Combining SAR Imagery and Ancillary Data. IEEE Trans. Geosci. Remote Sens. 2016, 54, 3612-3625. [CrossRef]

32. D'Addabbo, A.; Refice, A.; Lovergine, F.P.; Pasquariello, G. DAFNE: A Matlab Toolbox for Bayesian Multi-Source Remote Sensing and Ancillary Data Fusion, with Application to Flood Mapping. Comput. Geosci. 2018, 112, 64-75. [CrossRef]

33. Eilander, D.; Annor, F.O.; Iannini, L.; van de Giesen, N. Remotely Sensed Monitoring of Small Reservoir Dynamics: A Bayesian Approach. Remote Sens. 2014, 6, 1191-1210. [CrossRef]

34. Amitrano, D.; Cecinati, F.; di Martino, G.; Iodice, A.; Mathieu, P.P.; Riccio, D.; Ruello, G. Feature Extraction from Multitemporal SAR Images Using Selforganizing Map Clustering and Object-Based Image Analysis. IEEE J. Sel. Top. Appl. Earth Obs. Remote Sens. 2018, 11, 1556-1570. [CrossRef]

35. Lehmann, E.A.; Caccetta, P.A.; Zhou, Z.S.; McNeill, S.J.; Wu, X.; Mitchell, A.L. Joint Processing of Landsat and ALOS-PALSAR Data for Forest Mapping and Monitoring. IEEE Trans. Geosci. Remote Sens. 2012, 50, 55-67. [CrossRef]

36. Errico, A.; Angelino, C.V.; Cicala, L.; Persechino, G.; Ferrara, C.; Lega, M.; Vallario, A.; Parente, C.; Masi, G.; Gaetano, R.; et al. Detection of Environmental Hazards through the Feature-Based Fusion of Optical and SAR Data: A Case Study in Southern Italy. Int. J. Remote Sens. 2015, 36, 3345-3367. [CrossRef]

37. Dasgupta, A.; Grimaldi, S.; Ramsankaran, R.A.A.J.; Pauwels, V.R.N.; Walker, J.P. Towards Operational SAR-Based Flood Mapping Using Neuro-Fuzzy Texture-Based Approaches. Remote Sens. Environ. 2018, 215, 313-329. [CrossRef]

38. Liu, Z.; Li, G.; Mercier, G.; He, Y.; Pan, Q. Change Detection in Heterogenous Remote Sensing Images via Homogeneous Pixel Transformation. IEEE Trans. Image Processing 2018, 27, 1822-1834. [CrossRef] [PubMed]

39. Ganesan, P.; Rajini, V. Assessment of Satellite Image Segmentation in RGB and HSV Color Space Using Image Quality Measures. In Proceedings of the 2014 International Conference on Advances in Electrical Engineering, ICAEE 2014, Vellore, India, 9-11 January 2014; pp. 1-5. [CrossRef]

40. Agapiou, A. Multi-Temporal Change Detection Analysis of Vertical Sprawl over Limassol City Centre and Amathus Archaeological Site in Cyprus during 2015-2020 Using the Sentinel-1 Sensor and the Google Earth Engine Platform. Sensors 2021, $21,1884$. [CrossRef] [PubMed]

41. Olthof, I.; Fraser, R.H. Detecting Landscape Changes in High Latitude Environments Using Landsat Trend Analysis: 2. Classification. Remote Sens. 2014, 6, 11558-11578. [CrossRef]

42. Small, C.; Sousa, D. Humans on Earth: Global Extents of Anthropogenic Land Cover from Remote Sensing. Anthropocene 2016, 14, 1-33. [CrossRef]

43. Charrier, L.; Godet, P.; Rambour, C.; Weissgerber, F.; Erdmann, S.; Koeniguer, E.C. Analysis of Dense Coregistration Methods Applied to Optical and SAR Time-Series for Ice Flow Estimations. In Proceedings of the 2020 IEEE Radar Conference (RadarConf20), Florence, Italy, 21-25 September 2020; pp. 6-11. [CrossRef]

44. Gorelick, N.; Hancher, M.; Dixon, M.; Ilyushchenko, S.; Thau, D.; Moore, R. Google Earth Engine: Planetary-Scale Geospatial Analysis for Everyone. Remote Sens. Environ. 2017, 202, 18-27. [CrossRef]

45. Mutanga, O.; Kumar, L. Google Earth Engine Applications. Remote Sens. 2019, 11, 591. [CrossRef]

46. Henits, L.; Jürgens, C.; Mucsi, L. Seasonal Multitemporal Land-Cover Classification and Change Detection Analysis of Bochum, Germany, Using Multitemporal Landsat TM Data. Int. J. Remote Sens. 2016, 37, 3439-3454. [CrossRef]

47. Zepp, H.; Inostroza, L. Who Pays the Bill? Assessing Ecosystem Services Losses in an Urban Planning Context. Land 2021, 10, 369. [CrossRef]

48. ESRI OpenStreetMap Contributors v2 (c), Microsoft, Contributors, Esri Community Maps. Available online: https://cdn.arcgis $\mathrm{com} /$ sharing/rest/content/items/3e1a00aeae81496587988075fe529f71/resources/styles/root.json (accessed on 1 February 2022).

49. Land NRW-Digitale Orthophotos-Dl-de/Zero-2-0. Available online: https://www.bezreg-koeln.nrw.de/brk_internet/geobasis/ luftbildinformationen/aktuell/digitale_orthophotos/index.html (accessed on 1 February 2022).

50. Google Developers Sentinel-1 SAR GRD: C-Band Synthetic Aperture Radar Ground Range Detected, Log Scaling. Available online: https:/ / developers.google.com/earth-engine/datasets/catalog/COPERNICUS_S1_GRD (accessed on 1 February 2022).

51. ESA. ESA's Radar Observatory Mission for GMES Operational Services; ESA Communications: Leiden, The Netherlands, 2012; Volume 1, ISBN 9789292214180.

52. ESA Copernicus Open Access Hub. Available online: https://scihub.copernicus.eu/dhus/\#/home (accessed on 1 February 2022).

53. Land NRW-Hausumringe HU NW-Dl-de/Zero-2-0. Available online: https://www.opengeodata.nrw.de/produkte/geobasis/ lk/hu_shp/ (accessed on 1 February 2022).

54. Land NRW-Normalisiertes Digitales Oberflächenmodell-Dl-de/Zero-2-0. Available online: https://www.bezreg-koeln.nrw.de/ brk_internet/geobasis/hoehenmodelle/digitale_oberflaechenmodelle/normalisiertes_digitales_oberflaechenmodell/index. html (accessed on 1 February 2022).

55. Esch, T.; Schenk, A.; Ullmann, T.; Thiel, M.; Roth, A.; Dech, S. Characterization of Land Cover Types in TerraSAR-X Images by Combined Analysis of Speckle Statistics and Intensity Information. IEEE Trans. Geosci. Remote Sens. 2011, 49, 1911-1925. [CrossRef]

56. Esch, T.; Bachofer, F.; Heldens, W.; Hirner, A.; Marconcini, M.; Palacios-Lopez, D.; Roth, A.; Üreyen, S.; Zeidler, J.; Dech, S.; et al. Where We Live-A Summary of the Achievements and Planned Evolution of the Global Urban Footprint. Remote Sens. 2018, 10, 895. [CrossRef] 
57. Marconcini, M.; Metz-Marconcini, A.; Üreyen, S.; Palacios-Lopez, D.; Hanke, W.; Bachofer, F.; Zeidler, J.; Esch, T.; Gorelick, N.; Kakarla, A.; et al. Outlining Where Humans Live, the World Settlement Footprint 2015. Sci. Data 2020, 7, 242. [CrossRef] [PubMed]

58. Strano, E.; Simini, F.; de Nadai, M.; Esch, T.; Marconcini, M. The Agglomeration and Dispersion Dichotomy of Human Settlements on Earth. Sci. Rep. 2020, 11, 23289. [CrossRef] [PubMed]

59. Palacios-Lopez, D.; Bachofer, F.; Esch, T.; Heldens, W.; Hirner, A.; Marconcini, M.; Sorichetta, A.; Zeidler, J.; Kuenzer, C.; Dech, S.; et al. New Perspectives for Mapping Global Population Distribution Using World Settlement Footprint Products. Sustainability 2019, 11, 56. [CrossRef]

60. Land NRW-1937-2016: Deutsche Grundkarte 1:5000-Dl-de/Zero-2-0. Available online: https://www.bezreg-koeln.nrw.de/brk_ internet/geobasis/topographische_karten/historisch/1937/index.html (accessed on 1 February 2022).

61. DLR GUF Data and Access. Available online: https://www.dlr.de/eoc/en/desktopdefault.aspx/tabid-11725/20508_read-47944/ (accessed on 1 February 2022).

62. Che, M.; Gamba, P. Bi- and three-dimensional urban change detection using sentinel-1 SAR temporal series. GeoInformatica 2021, 25, 759-773. [CrossRef]

63. Juergens, C.; Meyer-Heß, M.F. Identification of Construction Areas from VHR-Satellite Images for Macroeconomic Forecasts Remote Sens. 2021, 13, 2618. [CrossRef]

64. Di Martino, T.; Colin-Koeniguer, E.; Guinvarch, R.; Thirion-Lefevre, L. REACTIV Algorithm. arXiv 2020, arXiv:1904.11335v2.

65. Koeniguer, E.C. REACTIV Code. Available online: https://code.earthengine.google.com/29923deb406fd4803a9b8963cdb50a12 (accessed on 1 February 2022).

66. Geobasis NRW Informationen Zur Bearbeitung von Gemeldeten Kartenfehlern. 2020, pp. 1-4. Available online: https:// www.bezreg-koeln.nrw.de/brk_internet/tim-online/timonline_information_tim_bearbeitung_kartenfehler.pdf (accessed on 1 February 2022).

67. Knöfel, P.; BKG; Herrmann, D. GAF Projekt Landschafts Ver Änderungs Dienst. 2020. Available online: https://subs.emis.de/ LNI/Proceedings/Proceedings238/P-238.pdf (accessed on 1 February 2022).

68. BKG; Geodäsie, B. Für K. und Landschaftsveränderungsdienst (LaVerDi). Available online: https://gdz.bkg.bund.de/index. php/default/landschaftsveraenderungsdienst.html (accessed on 1 February 2022).

69. Knöfel, P.; BKG. Vorstellung Des LandschaftsVeränderungsDienstes Des BKG-LaVerDi LaVerDi-Landschaftsveränderungsdienst Hauptziel: Kontinuierliche und Automatisierte Analyse von Landschaftsveränderungen Mit. 2020. Available online: https: //www.d-geo.de/arbeitstreffen/47/P15_Kn\%C3\%B6fel_LaVerDi.pdf (accessed on 1 February 2022).

70. Chini, M.; Pelich, R.; Hostache, R.; Matgen, P.; Lopez-Martinez, C. Towards a 20 m Global Building Map from Sentinel-1 SAR Data. Remote Sens. 2018, 10, 1833. [CrossRef] 